Proceedings of the Institution of Mechanical Engineers, Part D: Journal of Automobile Engineering

Volume 233, Issue 11, September 2019, pp. 2820-2837

DOI: $10.1177 / 0954407018804007$

\title{
Modelling Boundary-Layer Transition on Wings Operating in Ground Effect at Low
}

\section{Reynolds Numbers}

\author{
L. S. Roberts, M. V. Finnis, \& K. Knowles \\ Aeromechanical Systems Group, Centre for Defence Engineering, Cranfield University, \\ Defence Academy of the United Kingdom, Shrivenham, SN6 8LA. UK. \\ Contact: 1.roberts@cranfield.ac.uk
}

\begin{abstract}
The transition-sensitive, three-equation $k-k_{L}-\omega$ eddy-viscosity closure model was used for simulations of threedimensional, single-element and multi-element wing configurations operating in close proximity to the ground. The aim of the study was to understand whether the model correctly simulated the transitional phenomena that occurred in the low-Reynolds-number operating conditions, and whether it offered an improvement over the classical fully-turbulent k- $\omega$ SST model. This was accomplished by comparing the simulation results to experiments conducted in a $2.7 \mathrm{~m} \times 1.7 \mathrm{~m}$ closed-return, three-quarter-open-jet wind tunnel. The model was capable of capturing the presence of a laminar separation bubble on the wing and predicted sectional forces and surface-flow structures generated by the wings in wind tunnel testing to within $2.5 \%$ in downforce and $4.1 \%$ in drag for a multi-element wing. It was found, however, that the model produced insufficient turbulent kinetic energy during shear-layer reattachment, predicted turbulent trailing-edge separation prematurely in areas of large adverse pressure gradients, and was found to be very sensitive to inlet turbulence quantities. Despite these deficiencies the model gave results that were much closer to wind-tunnel tests than those given by the fullyturbulent k- $\omega$ SST model, which tended to under-estimate downforce. Significant differences between the transitional and fully-turbulent models in terms of pressure field, wake thickness, and turbulent kinetic energy production were found and highlighted the importance of using transitional models for wings operating at low Reynolds numbers in ground effect. The k-kL- $\omega$ model has been shown to be appropriate for the simulation of separation-induced transition on a three-dimensional wing operating in ground effect at low Reynolds number.
\end{abstract}

\section{Keywords}

Boundary layer, turbulence, closure model, wind tunnel, laminar separation bubble, Reynolds number 


\section{Nomenclature}

c Total chord of main-plane element [m]

$C_{D} \quad$ Drag coefficient $\left(\frac{D}{q_{\infty} S}\right)$

$C_{L} \quad$ Lift coefficient $\left(\frac{L}{q_{\infty} S}\right)$

$C_{P} \quad$ Pressure coefficient $\left(\frac{\Delta P}{q_{\infty}}\right)$

$\Delta C_{P} \quad \mathrm{C}_{\mathrm{P}}\left(k-k_{L^{-}} \omega\right)-\mathrm{C}_{\mathrm{P}}(k-\omega S S T)$

D Drag force [N]

$D_{L} \quad$ Anisotropic (near-wall) dissipation term for $k_{L}$

$D_{T} \quad$ Anisotropic (near-wall) dissipation term for $k$

$f_{w} \quad$ Inviscid near-wall damping function

$f_{\omega} \quad$ Boundary layer wake term damping function in $\omega$ equation

$\mathrm{h} \quad$ Ground clearance [m]

$k \quad$ Turbulent kinetic energy $\left[\mathrm{m}^{2} \mathrm{~s}^{-2}\right]$

$\Delta k \quad k\left(k-k_{L^{-}} \omega\right)-k(k-\omega S S T)\left[\mathrm{m}^{2} \mathrm{~s}^{-2}\right]$

$k_{L} \quad$ Laminar kinetic energy $\left[\mathrm{m}^{2} \mathrm{~s}^{-2}\right]$

$l \quad$ Turbulence length scale $[\mathrm{m}]$

L Lift Force (positive upwards) [N]

$\Delta \mathrm{P} \quad$ Local static pressure relative to freestream $\left[\mathrm{Nm}^{-2}\right]$

$\mathrm{P}_{0} \quad$ Total pressure $\left[\mathrm{Nm}^{-2}\right]$

$\Delta \mathrm{P}_{0} \quad \mathrm{P}_{0}\left(k-k_{L^{-}} \omega\right)-\mathrm{P}_{0}(k-\omega S S T)\left[\mathrm{Nm}^{-2}\right]$

$P_{k_{L}}$

Production of laminar kinetic energy by mean strain

$P_{k_{T}}$

Production of turbulent kinetic energy by mean strain

$q_{\infty}$

Freestream dynamic pressure $\left[\mathrm{Nm}^{-2}\right]$

$R_{B P} \quad$ Bypass transition production term

$R_{N A T} \quad$ Natural transition production term

$\mathrm{s} \quad$ Wing semi-span [m]

$\mathrm{S} \quad$ Wing planform area $\left[\mathrm{m}^{2}\right]$

$\mathrm{Tu} \quad$ Turbulence intensity [\%]

$U_{\infty} \quad$ Freestream velocity $\left[\mathrm{ms}^{-1}\right]$

$U_{*} \quad$ Shear velocity $(\sqrt{\tau / \rho})\left[\mathrm{ms}^{-1}\right]$

$x_{L} / c \quad$ Chordwise bubble length

$x_{R} / c \quad$ Chordwise reattachment point

$x_{S} / c \quad$ Chordwise separation point

$y_{f} / c \quad$ Local, normalised flowfield y coordinate

$\mathrm{x}, \mathrm{y}, \mathrm{z} \quad$ Cartesian coordinates ( $\mathrm{x}$ - downstream, $\mathrm{y}$ - vertically down, $\mathrm{z}$ - horizontal), origin at centreline and leading edge of wing main-plane

$\mathrm{X} \quad$ Total model length (leading edge of wing to trailing edge of non-metric body, equal to $4.55 \mathrm{c}$ )

$\mathrm{Y}^{+} \quad$ Dimensionless wall distance $\left(\frac{U_{*} Y}{v}\right)$

$\mathrm{Y} \quad$ Distance to nearest wall [m]

Re Chord-based Reynolds number $\left(\frac{U_{\infty} c}{v}\right)$

$\alpha_{T} \quad$ Effective diffusivity for turbulence-dependent variables

$v \quad$ Kinematic viscosity $\left[\mathrm{m}^{2} \mathrm{~s}^{-1}\right]$

$\rho \quad$ Density $\left[\mathrm{kg} \mathrm{m}^{-3}\right]$

$\tau \quad$ Shear stress $\left[\mathrm{Nm}^{-2}\right]$

$\omega \quad$ Specific dissipation rate $\left[\mathrm{s}^{-1}\right]$

\section{$\boldsymbol{k}-\boldsymbol{k}_{\boldsymbol{L}}-\boldsymbol{\omega}$ model constants}

$C_{\omega 1}=0.44 \quad C_{\omega \mathrm{R}}=1.5 \quad C_{\omega 2}=0.92 \quad C_{\omega 3}=0.3 \quad \sigma_{k}=1 \quad \sigma_{\omega}=1.17$ 


\section{INTRODUCTION}

The aerodynamic analysis of wings operating in ground effect has previously been conducted through both experimental and computational means [1-23]. The computational studies [13-23] have, in general, used Reynolds-Averaged Navier Stokes (RANS) solvers with fully-turbulent closure models, the low Reynolds number operating conditions for such simulations means that in reality there are both laminar and turbulent effects to consider. Experimental studies [9-13], however, have shown that both laminar and turbulent boundary layers exist on the wing, with transition occurring through a laminar separation bubble. In comparison to a turbulent boundary layer, laminar boundary layers are thinner, generate lower skin friction drag, and are less resilient to adverse pressure gradients; thus if a significant portion of the wing contains a laminar boundary layer, then the assumption of fully-turbulent flow can lead to erroneous results. The development of transitionsensitive eddy-viscosity closure models for use in commercially-available RANS solvers has meant that such effects can now be modelled with relatively modest computational cost. Whilst these models have been used extensively in the aeronautical and turbomachinery sectors [24-30], there is a lack of literature for ground-effect aerofoils, where transitional effects are altered by the large pressure gradients that are produced. Even the most recent computational studies of inverted wings in ground effect [31, 32] have made use of fully-turbulent closure models despite operating at a Reynolds number at which transitional phenomena are still prevalent and, in the case of the latter study, observing the effect of Reynolds number scaling. Despite the low Reynolds number conditions of each of these studies, none has included natural transition phenomena as a laminar region was only included up to $\mathrm{x} / \mathrm{c}=0.1$ such that comparison could be made to forced-transition experiments.

Experimental studies that have used boundary-layer trips to cause premature transition to a turbulent boundary layer [9-12] have cited large differences in the aerodynamic forces and flow structures compared to the natural transition counterpart. Zerihan \& Zhang [9] found increased trailing-edge separation when the turbulent boundary layer covered a larger portion of the wing, due to a thicker boundary layer encountering the adverse pressure gradient. Correia et al. [10] showed the laminar separation bubble to be a force-enhancement mechanism as it altered the effective shape of the wing akin to an increase in camber, thus increasing circulation.

Moreover,

Roberts et al. [11-12] showed that a wing with a longer turbulent portion gave a thicker wake and a significantly different pressure field around the wing. Additionally, the aerodynamic forces generated by the wing were proportional to the extent of the laminar boundary layer. 
The aim of the present study is to assess the performance of the transition-sensitive $k-k_{L^{-}} \omega$ model, for use on complex three-dimensional wing geometries operating in ground effect, through comparison with experiments conducted in a 50\% scale automotive wind tunnel. Additionally, the work aims to understand the importance of using transition-sensitive models in comparison with results gathered using the fully-turbulent $k$ - $\omega S S T$ model.

\subsection{Overview of the $k-k_{L^{-}} \omega$ model}

The model used in this study is that of Walters \& Cokljat [33], which itself was based on a concept first proposed by Walters \& Leylek [34]. Based on the $k$ - $\omega$ framework, the $k-k_{L}-\omega$ model is a purely physics-based eddy-viscosity turbulence model that employs three transport equations for turbulent kinetic energy $(k)$, laminar kinetic energy $\left(k_{L}\right)$, and the scale-determining variable, also interpreted as the specific dissipation rate $(\omega)$. The additional transport equation, compared to the typical two-equation $k$ - $\omega$ models, is included to model pretransitional phenomena such as Klebanoff modes and Tollmien-Schlichting waves. An additional feature of the $k-k_{L^{-}} \omega$ model is that it includes anisotropic dissipation constants.

In the first two transport equations the model takes into account the production of both turbulent and laminar kinetic energy through both the amplification of low-frequency disturbances in the boundary layer and the selectivity of the boundary layer to freestream eddies. It is, therefore, capable of modelling both natural and bypass transition. The model characterises the transition process as the transfer of laminar kinetic energy into turbulent kinetic energy due to increasing pressure-strain terms. The initiation of this process is based on the restriction of turbulence damping functions and growth of these pressure-strain terms in the Reynolds stress terms.

$$
\begin{gathered}
\frac{D\left(k_{T}\right)}{D t}=\frac{\partial}{\partial x_{j}}\left[\left(v+\frac{\alpha_{T}}{\sigma_{k}}\right) \frac{\partial k}{\partial x_{j}}\right]+P_{k_{T}}+R_{B P}+R_{n a t}-\omega k-D_{T} \\
\frac{D\left(k_{L}\right)}{D t}=\frac{\partial}{\partial x_{j}}\left[v \frac{\partial k_{L}}{\partial x_{j}}\right]+P_{k_{L}}-R_{B P}-R_{n a t}-D_{L}
\end{gathered}
$$

The third equation, for the scaling variable $\omega$, is given below. The first, third and fifth terms of the equation represent the production, destruction and gradient transport terms, and are analogous to the similar terms of the $k_{L}$ and $k_{T}$ equations. They are also similar to the terms that appear in other models based on the $k$ - $\omega$ framework. 


$$
\begin{aligned}
\frac{D \omega}{D t}=C_{\omega 1} \frac{\omega}{k} P_{k_{T}} & +\left(\frac{C_{\omega R}}{f_{w}}-1\right) \frac{\omega}{k}\left(R_{B P}+R_{N A T}\right)-C_{\omega 2} \omega^{2}+C_{\omega 3} f_{\omega} \alpha_{T} \frac{f^{2} w \sqrt{k}}{d^{3}} \\
& +\frac{\partial}{\partial x_{j}}\left[\left(v+\frac{\alpha_{T}}{\sigma_{k}}\right) \frac{\partial k}{\partial x_{j}}\right]
\end{aligned}
$$

The values of $k, k_{L}$, and $\omega$ are specified at the inlet. For $k$ and $\omega$ this is analogous to other two-equation models. In the present study $k$ is determined by the turbulence intensity $(I)$ through the relationship given in Equation 4 , and $\omega$ found from Equation 5 by estimating the turbulence length scale $(l)$.

$$
\begin{gathered}
k=\frac{3}{2}\left(U_{\infty} T u\right)^{2} \\
\omega=\frac{k^{1 / 2}}{C_{\mu}{ }^{1 / 4} l}
\end{gathered}
$$

Where $C_{\mu}=0.09$

\section{METHODS}

\subsection{Test Models}

Three-dimensional untapered, untwisted, rectangular planform, $\mathrm{GA}(\mathrm{W})-1$ section wing configurations were used in this study. The wing section, which measures $750 \mathrm{~mm}$ in span and $119.7 \mathrm{~mm}$ in chord, is set at $-0.5^{\circ}$ incidence and fitted with simple rectangular endplates at either end. This forms the basis of the single-element wing, and the main-plane of the multi-element wing; the latter is then combined with a pair of constant-crosssection Reynard Racing 'Kylie' flaps each of span $250 \mathrm{~mm}$, chord $160 \mathrm{~mm}$ and set at $23.9^{\circ}$ incidence. Each flap is mounted off an endplate, with additional support from a bracket connected to the main-plane. Diagrams of the models are given in Figure 1. The wing is suspended by two vertical pylons from a six-component Aerotech force balance, which in turn is mounted to the bottom of a large overhead strut. The force balance is housed inside a non-metric streamlined body to separate it from interaction with the airflow. The body is mounted from the overhead strut and has no contact with neither the force balance or wing pylons, hence, whilst it has an aerodynamic effect on the wing the forces that it produces are not measured by the balance. 

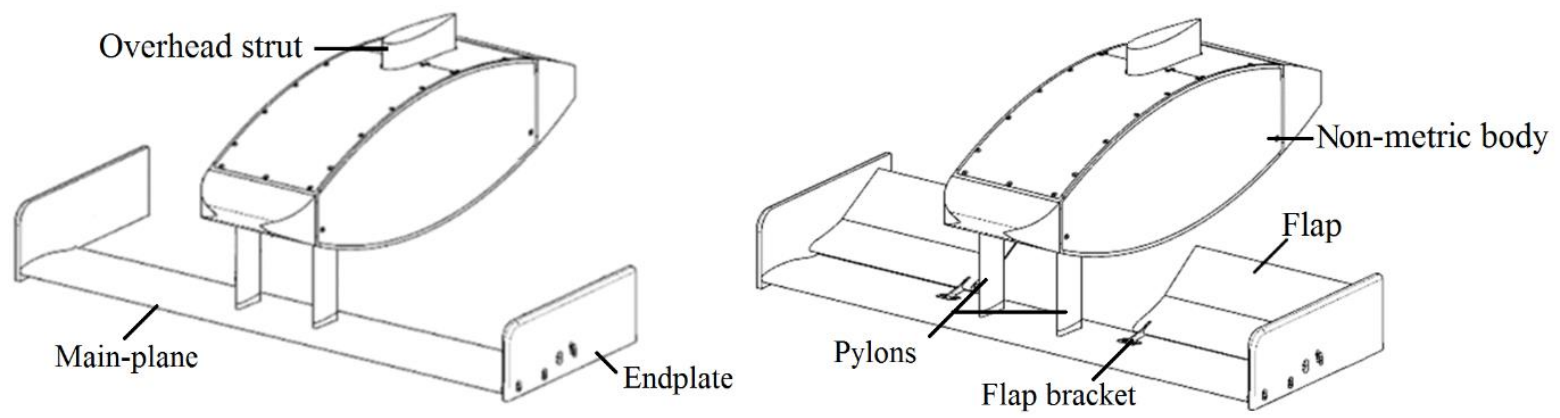

Figure 1 - Diagram of single-element (left) and multi-element (right) wing assemblies

\subsection{Description of Experiments}

\subsubsection{Test Facility}

Wind tunnel experiments were conducted in Cranfield University's DS Houghton wind tunnel. This facility, which is located at the Defence Academy of the United Kingdom in Shrivenham, UK, was originally designed to cater for $50 \%$ scale open-wheel racing car models. It is a $2.7 \mathrm{~m} \mathrm{x} 1.7 \mathrm{~m}$ closed-return, three-quarter-open-jet tunnel with a continuous-belt rolling road synchronised with the freestream wind velocity. Boundary-layer suction is applied through perforated plates ahead of the road. This suction has been optimised and combined with a knife-edge transition to the road, such that it gives a residual boundary-layer thickness of $1.58 \mathrm{~mm}$ at the leading edge of the model. Freestream turbulence is measured to be $0.3 \%$ at the centre of the test-section. Models can be mounted to the overhead strut, which also incorporates a motion control system that allows alteration of the model height relative to the tunnel floor during a test i.e. wind on. Further information on this tunnel is given by Knowles \& Finnis [35].

\subsubsection{Experimental Method and Uncertainties}

Downforce and drag measurements were taken at a range of Reynolds numbers, based on the main-plane chord length, from $\operatorname{Re}=1.63 \times 10^{5}$ to $\operatorname{Re}=2.44 \times 10^{5}$ at a non-dimensional ground clearance of $h / c=0.3125$. These Reynolds numbers are equivalent to a velocity range of $20 \mathrm{~ms}^{-1}$ to $30 \mathrm{~ms}^{-1}$ at standard atmospheric conditions. The wind tunnel control system automatically controlled the freestream wind velocity such that the Reynolds number remained constant i.e. was not altered by changes in ambient temperature or pressure. The uncertainty in Reynolds number, based on the maximum measured error during the tests, was \pm 470 .

The wing was mounted in the tunnel with an orientation uncertainty of $\pm 0.0047^{\circ}$ in pitch and $\pm 0.0038^{\circ}$ in roll. These uncertainties were determined by measuring the distance between the wind tunnel floor and four 
control points on the wing: two at either end, front and rear. Measurements were taken before and after the experiment to ensure that the orientation had not altered unacceptably. The yaw angle of the wing was measured to be within $\pm 0.0023^{\circ}$ of parallel to the wind tunnel centreline. This was determined by taking the distance from the endplate to the edge of the rolling road; measurements were taken at each end and at the front and rear of the endplate.

The experimental uncertainty was determined through a parametric study of each variable, including roll, pitch, yaw, and dynamic pressure. Forces were recorded at multiple settings of each variable and then the variation between the forces assumed to be linear. The results of this study were combined with the accuracies stated above to give the uncertainty due to each variable. These where then combined with the force balance error to give an overall uncertainty of downforce and drag coefficients of \pm 0.014 and \pm 0.0023 respectively at a 95\% confidence level. Repeatability tests, which consisted of ten back-to-back ground-clearance sweeps of the same setup, were performed. The largest difference to the mean value recorded was 0.026 in downforce coefficient and 0.011 in drag coefficient.

A paint consisting of fluorescent pigment, oleic acid and paraffin was used to perform flow visualisation on the suction surface of the wing assembly. The paint was sprayed onto the surfaces immediately prior to the wind being switched on. The wind then caused the paraffin to evaporate, which left the dried pigment on the surface. Once the wing was removed to a dark room and placed under ultra-violet light the pigment showed the flowpattern. Images of the wing were then taken and transformed into an 8-bit grey-scale using image-processing software. A histogram equalisation technique was used in order to reduce the number of grey shades and highlight the detail of the streamlines more clearly.

\subsection{Description of Computations}

RANS simulations were performed using ANSYS Fluent 15.0.7 on a dedicated Linux-based cluster at Cranfield University, with a total of 1280 cores and peak performance of 18.8 TFlops. Simulations in this study made use of 64 CPU cores and 256 GB of shared memory.

\subsubsection{Grid Generation}

A fully-unstructured grid was created around a CAD model of the wing geometry. Only half of the wing was considered in order to reduce the number of elements required, as it is assumed that flow is symmetrical about the wing's symmetry plane. In order to simplify the grid and reduce the number of elements required the 
overhead strut was omitted from the computational model along with smaller features (on the pressure surface) such as brackets and holes.

The domain extends $7 \mathrm{X}$ (total model lengths) downstream from the rearmost point of the model and $3 \mathrm{X}$ upstream of the leading edge of the wing. This ensured that the model's presence did not influence the inlet and outlets such that constant pressure was maintained. The domain width was $3 \mathrm{X}$ from the wing centreline and $3 \mathrm{X}$ in total height. This gave a blockage of $3.7 \%$ to ensure that no pressure gradients reached the top and side of the domain.

A total of $3.2 \times 10^{7}$ and $4.1 \times 10^{7}$ elements were used in the final meshes for the single- and multi-element wing configurations respectively. Triangular surface elements on all wing surfaces were set to a maximum size of $0.75 \mathrm{~mm}$ and minimum of $0.1 \mathrm{~mm}$. A total of 21 prism layers were grown from the wing surfaces at a growth rate of $20 \%$ and an initial height such that a $\mathrm{Y}^{+}<1$ was maintained at all times. The total prism layer height was enough to capture the entire boundary-layer profile, up to $99 \%$ of freestream velocity, at all points along the wing. Prism layers were also placed on the ground underneath the wing so that the residual boundary layer, which forms as a result of the higher-than-freestream velocities that are produced under the wing, is modelled correctly. A total of 10 prism layers with a $\mathrm{Y}^{+}<1$ were used; again, this ensured that the entire boundary layer height was contained inside the prism layers. The tetrahedral volume elements immediately around the wing were refined to a maximum size of $1 \mathrm{~mm}$ close to the wing, $5 \mathrm{~mm}$ in the near-field, and finally growing at a maximum rate of $20 \%$ towards the far-field and domain boundaries. Cut planes of the final meshes for each wing configuration are shown in Figure 2. 

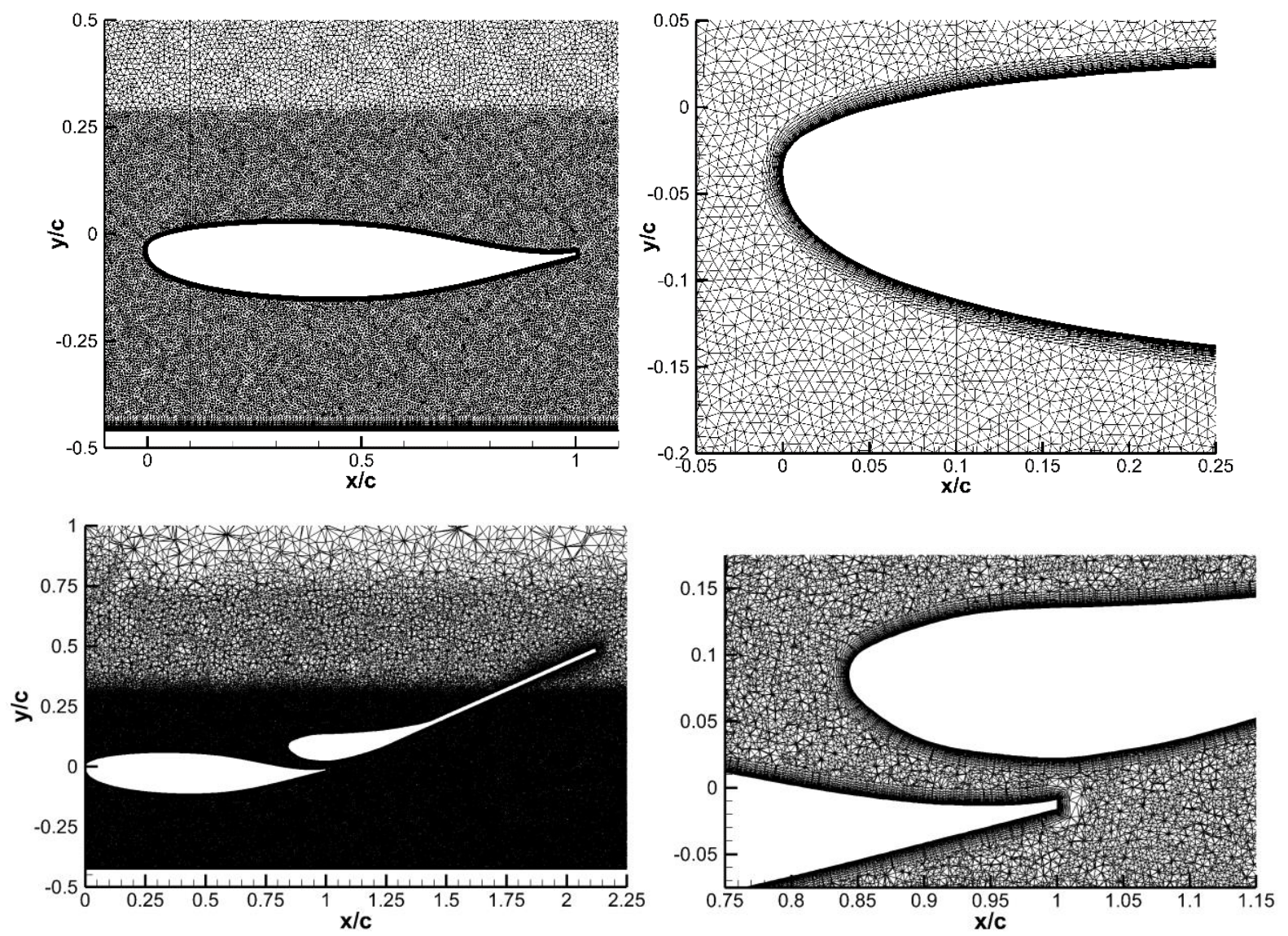

Figure 2 - Cut-plane of computational grid close to wing at symmetry plane for the single-element wing (top) and at flap centreline $(z / s=2 / 3)$ for the multi-element wing (bottom)

A mesh-independent solution was determined by systematically altering individual parameters from an initially very fine mesh. This approach was taken as the lack of time constraints on the project meant that a very fine mesh could be used from the outset, and a coarser mesh ( $\sim 30 \%$ fewer elements) did not have to be found. As no considerable changes were observed in the aerodynamic forces or surface-flow features the mesh was deemed sufficient such that it did not affect the final solution. The maximum $\mathrm{Y}^{+}$value attained on any wing surface of the grid is 0.7; a maximum of 0.2 was trialled and did not affect the solution. The number of prism layers was fixed in order to give a total height that encased the entire boundary layer. Refinement of tetrahedral volume elements in the regions around the wing was completed. The level of volume refinement did not appear to influence these aspects, however to ensure an accurate representation of wake structures and limit the truncation error causing artificial dissipation of vortices the finer mesh was retained.

\subsubsection{Boundary Conditions}

As only half the wing geometry had been discretised a symmetry condition was applied at the symmetry plane. A symmetry condition was also placed on the far-side and roof boundaries as this results in a zero-flux of 
quantities across the boundary. The moving ground was replicated by a no-slip wall translating with the same direction and speed as the freestream flow. Flow entered the domain through a velocity inlet, where turbulence quantities were prescribed as $k=1.215 \mathrm{~m}^{2} \mathrm{~s}^{-2}, k_{L}=10^{-6} \mathrm{~m}^{2} \mathrm{~s}^{-2}$ (where applicable), and $\omega=2.012 \mathrm{~s}^{-1}$ unless otherwise stated. Inlet conditions are discussed further in Section 3.2. Flow exited the domain through a pressure outlet.

\subsubsection{Numerical Method}

The flow-field was solved using a steady-state, incompressible, segregated solver in the three-dimensional finite-volume code Fluent. The SIMPLE scheme was used for pressure-velocity coupling, pressure terms discretized using the second-order scheme, and spatial gradients computed using a Green-Gauss node-based method. The convective terms of all equations used a second-order-upwind discretization scheme.

The flow-field was initialised with zero-velocity conditions, as recommended by Lanfrit [36], and then iterated 12,000 times. After this the lift and drag coefficients had become steady state and residuals all decreased below $10^{-5}$. The total computation time for each simulation was approximately 20 hours (wall clock).

\section{RESULTS \& DISCUSSION}

\subsection{Validation and Characteristics of Closure Model}

\subsubsection{Single-element wing}

The accuracy of the downforce and drag values of the CFD simulation compared to the same configuration in wind tunnel testing is shown in Table 1 . The downforce is over-predicted by CFD, with an error of $7.78 \%$, and the drag coefficient under-estimated, with an error $7.42 \%$. It should be considered, however, that the actual force values attained in the experiments for downforce and drag are only $31.12 \mathrm{~N}$ and $2.13 \mathrm{~N}$ respectively. The difference in predicted downforce and drag between the simulation and experiment is, therefore, only $2.42 \mathrm{~N}$ and $-0.159 \mathrm{~N}$ respectively.

Table 1 - Comparison of downforce and drag generated by single-element three-dimensional wing in CFD and wind tunnel experiments $\left(\mathrm{h} / \mathrm{c}=0.3125, \operatorname{Re}=2.44 \times 10^{5}\right)$

\begin{tabular}{c|c|c|c|c|c|} 
Case & $C_{D}$ & $-C_{L}$ & $x_{S} / c$ & $x_{R} / c$ & $x_{L} / c$ \\
\hline Experiment & 0.0431 & 0.627 & 0.564 & 0.783 & 0.219 \\
$k-k_{L^{-}} \omega$ & 0.0399 & 0.676 & 0.610 & 0.831 & 0.221
\end{tabular}




$$
\Delta \%\left(\frac{C F D-E x p}{E x p}\right)|-7.42| 7.78|7.16| 6.13 \mid 0.91
$$

As shown in Figure 3, surface-flow visualisation tests conducted in the wind tunnel showed that the transition mechanism for the single-element wing was a separation bubble. Figure 3 also shows that the transitional $k-k_{L^{-}} \omega$ model allows the occurrence of the separation bubble to be predicted. Overall, the surface-flow characteristics are represented well by the transitional model. Clearly the fundamental surface-flow structure found in wind tunnel testing is replicated by the $k-k_{L^{-}} \omega$ model; to understand how accurately this is predicted a comparison of the bubble size and location at the wing centreline is also given in Table 1 . The overall bubble length is very well predicted by the computational results, with the length of the bubble calculated to within $0.9 \%$ of that found in the experimental flow visualisation. The separation point in the computational result occurs $x / c=0.046$ further downstream than the experimental result and reattachment occurs $x / c=0.048$ later.

Figure 3 shows that the shear stresses on the wing's surface were accurately predicted such that surface streamlines showed good similarity to surface-flow visualisation from wind tunnel testing. The off-surface prediction of the bubble, shown by streamlines generated by velocity, is shown in Figure 4a. The region of recirculating air inside the bubble is captured; this acts to displace the off-surface streamlines and alter the effective shape of the wing, as previous studies have observed [10-11]. Contours of turbulent kinetic energy are given behind the streamlines, this shows how the production of turbulent kinetic energy begins just after the separation of the laminar boundary layer and how maximum turbulent kinetic energy is found during the reattachment. This is in accordance with what would be expected based on the structure of a separation bubble, as the instabilities produced during separation generate turbulence, which eventually leads to reattachment. The $k-k_{L}-\omega$ model is based on the redistribution of energy via a pressure-strain mechanism, as opposed to the production or dissipation of energy. Hence in the region before the bubble the total energy is contained in laminar kinetic energy, whilst after separation of the laminar boundary layer, energy is redistributed into turbulent kinetic energy in the separated shear layer. Such characteristics are also shown in Figure 4b, which plots turbulent kinetic energy and x-shear stress (in the chordwise direction) for the centreline of the wing's suction surface. The region of zero shear stress shows the location of the separation bubble; $\mathrm{x}$-shear stress was used in place of skin friction coefficient as the latter is influenced by the other components of stress inside the bubble, thus using the $\mathrm{x}$-component alone is a more accurate way to highlight the bubble. Near to the leading edge there is maximum shear stress as flow stagnates and then accelerates around the leading edge; moving downstream the shear stress decreases as the local Reynolds number increases and the boundary layer thickens. 
There is a small amount of turbulent kinetic energy produced at the leading edge, but this is dissipated due to the strong acceleration of flow that then occurs, then there is a lack of turbulent kinetic energy until transition occurs. As shown in Table 1, separation of the laminar boundary layer occurs at $x / c=0.610$ in the CFD model. Transition then begins to occur, as shown by the increase in turbulent kinetic energy, in the separated shear layer at $x / c \approx 0.675$. Maximum turbulent kinetic energy occurs at $x / c=0.779$, which is approximately $45 \%$ along the bubble's total length, and then reattachment of the now-turbulent boundary layer at $x / c=0.851$, as shown by the regrowth of shear stress. It is believed that the under-estimate of drag, shown in Table 1, is a consequence of the separation bubble being predicted at a location too far downstream. This leads to an under-prediction of shear stress in the turbulent boundary layer portion and, consequently, an under-prediction of skin-friction drag.

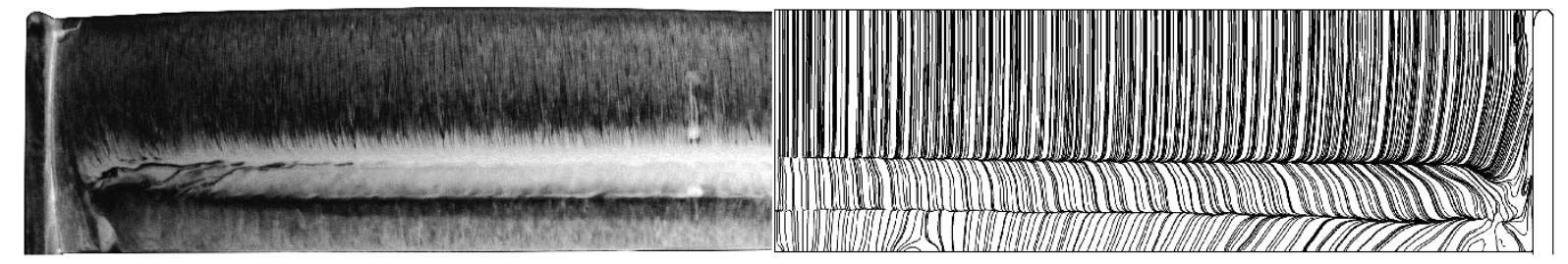

Figure 3 -Experimental flow visualisation (left) and CFD surface streamlines generated by shear stress (right) on suction surface of single-element wing $\left(\operatorname{Re}=2.44 \times 10^{5}, h / c=0.3125\right.$, freestream flow from top to bottom) 


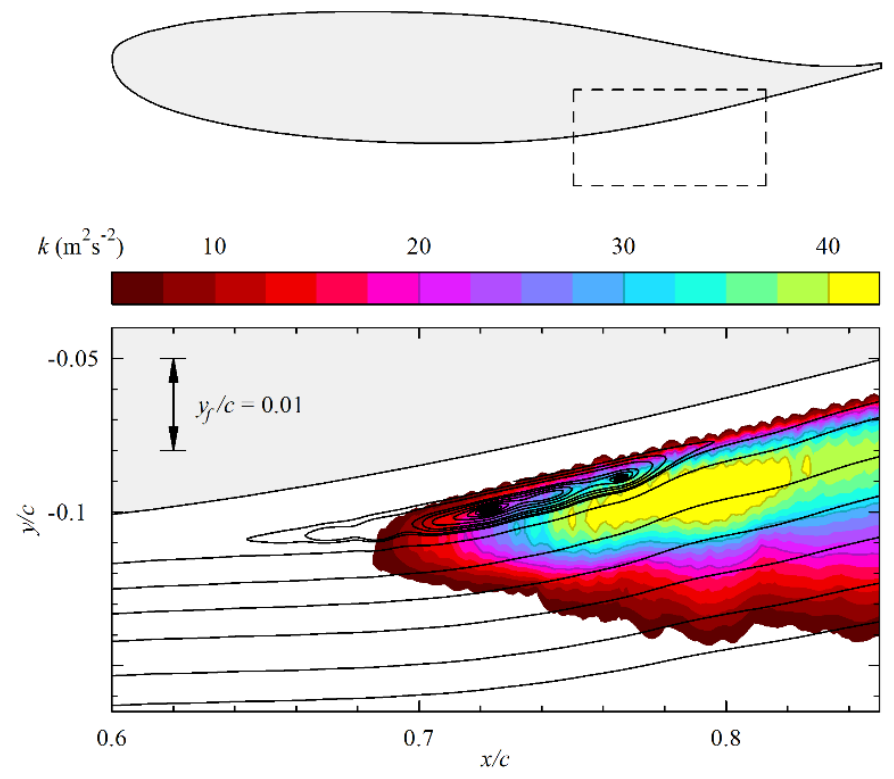

a)

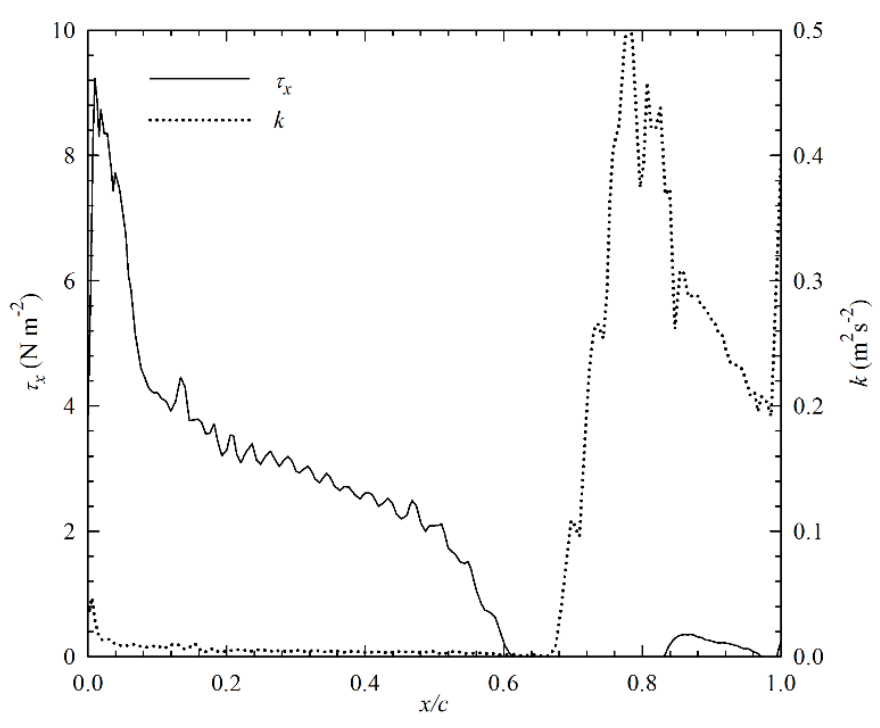

b)

Figure 4 - a) Streamlines, generated by $x$ and $y$ velocity, of separation bubble on suction surface with contours of turbulent kinetic energy (flowfield distorted for clarity - see footnote 1), and b) x-component of shear stress and turbulent kinetic energy along the centreline of the suction surface $\left(\operatorname{Re}=2.44 \times 10^{5}, h / c=0.3125, \mathrm{CFD}\right.$ results $)$

The Reynolds number depicts the ratio between viscous and inertial forces in a given flow. Transitional phenomena have a significant Reynolds number sensitivity as viscosity acts to dissipate turbulence and dampen instabilities in the flow whilst inertial forces promote turbulence production. Previous studies with the singleelement wing geometry used in this study by Correia et al. [10] showed it to have significant Reynolds-number dependency across the range $1.63 \times 10^{5}<\operatorname{Re}<2.44 \times 10^{5}$. As this dependency was attributed to altering of the separation bubble's size and location it is important that a computational model also responds to this. The force coefficients at various Reynolds numbers from wind tunnel tests and CFD simulations are shown in Table 2. Turbulence quantities were estimated using the same values of freestream turbulence intensity and turbulent length scale but the different speeds caused the specific values of $k$ and $\omega$ to be altered relative to freestream velocity.

\footnotetext{
${ }^{1}$ Note that for the contour plots in Figs $4,5 \& 7$ the flowfield (but not the body) has been distorted by stretching it in the y-direction by a factor of 3 to make the bubble easier to see. (Merely magnifying the entire axis would have exaggerated the slope of the wing; magnifying both axes would have made the plot unacceptably large.) Thus, the $y / c$ coordinate applies to the body; the size of the $y$-increment in the fluid is indicated by the $y_{f} / c$ dimension.
} 
Table 2 - Force coefficients at varying Reynolds number for wind tunnel tests and CFD simulation $(h / c=0.3125$, single-element wing)

\begin{tabular}{|c|c|c|c|c|c|}
\hline $\mathbf{R e}$ & & $C_{D}$ & $-C_{L}$ & $\begin{array}{c}\Delta \boldsymbol{C}_{\boldsymbol{D}} \\
\Delta \%\left(\frac{C F D-E x p}{E x p}\right)\end{array}$ & $\begin{array}{c}-\Delta C_{L} \\
\Delta \%\left(\frac{C F D-E x p}{E x p}\right)\end{array}$ \\
\hline $1.63 \times 10^{5}$ & $\begin{array}{c}\text { Experimental } \\
\qquad k-k_{L^{-}} \omega\end{array}$ & $\begin{array}{c}0.0639 \\
\pm 0.0023 \\
0.0473\end{array}$ & $\begin{array}{c}0.383 \\
\pm 0.014 \\
0.67\end{array}$ & $\begin{array}{c}- \\
-8.19\end{array}$ & $\begin{array}{c}- \\
72.18\end{array}$ \\
\hline $2.03 \times 10^{5}$ & $\begin{array}{l}\text { Experimental } \\
\qquad k-k_{L^{-}} \omega\end{array}$ & $\begin{array}{c}0.0485 \\
\pm 0.0023 \\
0.0432\end{array}$ & $\begin{array}{c}0.587 \\
\pm 0.014 \\
0.689\end{array}$ & $\begin{array}{c}- \\
-10.81\end{array}$ & $\begin{array}{c}- \\
17.37\end{array}$ \\
\hline $2.44 \times 10^{5}$ & $\begin{array}{c}\text { Experimental } \\
\qquad k-k_{L^{-}} \omega\end{array}$ & $\begin{array}{c}0.0431 \\
\pm 0.0023 \\
0.0399\end{array}$ & $\begin{array}{c}0.627 \\
\pm 0.014 \\
0.676\end{array}$ & $\begin{array}{c}- \\
-7.42\end{array}$ & 7.78 \\
\hline $2.85 \times 10^{5}$ & $\begin{array}{l}\text { Experimental } \\
\qquad k-k_{L^{-}} \omega\end{array}$ & $\begin{array}{c}0.0405 \\
\pm 0.0023 \\
0.0380\end{array}$ & $\begin{array}{c}0.646 \\
\pm 0.014 \\
0.692\end{array}$ & $\begin{array}{c}- \\
-6.42\end{array}$ & $\begin{array}{c}- \\
7.20\end{array}$ \\
\hline
\end{tabular}

As shown above, at the datum Reynolds number of $2.44 \times 10^{5}$ the drag and downforce were predicted to within 8\%. At lower Reynolds numbers, however, the calculation becomes poorer. This is due to much more complex flow characteristics that occur at the lower Reynolds number, in which the bubble reattaches as a turbulent boundary layer, but the adverse pressure gradient is still too great and a second separation occurs (see Figure 5). Such an occurrence is seen at both $\operatorname{Re}=1.63 \times 10^{5}$ and $\operatorname{Re}=2.03 \times 10^{5}$. For the higher Reynolds numbers, however, this does not occur and the turbulent boundary layer remains attached. The incorrect prediction of turbulent trailing-edge separation has long been a characteristic problem with RANS-based simulations for studies looking at increasing angle of attack to the point of stall [37]. In this study, failure to represent stall characteristics accurately has led to a large over-estimation of the downforce values.

Figure 5 shows the separation bubble through off-surface streamlines and contours of turbulent kinetic energy at varying Reynolds number. Although the force prediction of the lower Reynolds number cases is poor, some of the overall characteristics given are encouraging. The flow visualisation shows that for $\operatorname{Re}=1.63 \times 10^{5}$ and

$\operatorname{Re}=2.03 \times 10^{5}$ the bubble reattaches initially, but then quickly separates once again in what must be considered a turbulent trailing-edge separation. The computed surface streamlines, which are generated by shear stress, show a bubble that is much longer and does not ever fully reattach. Additionally, the bubble starts at a point 
further downstream than that seen in the flow visualisation. This has an impact on the reattachment characteristics of the bubble. The bubble length is increased, as it should be, but it is increased too much and this is possibly linked to the lower flow velocity at the edge of the boundary layer, due to it occurring at a location further into the pressure recovery region, reducing the Kelvin-Helmholtz instabilities that produce turbulence. There is a small degree of separated flow near to the trailing edge, but the overall lack of trailingedge separation in comparison to the experiments gives the over-estimate of downforce and under-estimate of drag.

Table 3 - Separation bubble size and location taken from surface-flow visualisation (experiments) and CFD $(h / c=$ 0.3125)

Experiment

CFD

\begin{tabular}{c|c|c|c|c|c|c}
$\mathrm{Re} \times 10^{-5}$ & $x_{S} / c$ & $x_{R} / c$ & $x_{L} / c$ & $x_{S} / c$ & $x_{R} / c$ & $x_{L} / c$ \\
\hline 1.63 & 0.5 & 0.747 & 0.247 & 0.599 & 0.975 & 0.376 \\
2.04 & 0.539 & 0.778 & 0.239 & 0.602 & 0.918 & 0.316 \\
2.44 & 0.558 & 0.785 & 0.227 & 0.610 & 0.831 & 0.221
\end{tabular}

Diwan \& Ramesh [38] showed that the length and height of a separation bubble increased with decreasing Reynolds number. Figure 5 shows that the CFD correctly replicated the increase in bubble height with reducing Reynolds number. As Table 3 shows, however, the change in bubble length in the experiments was only very small $(0.02 \mathrm{c})$, but in CFD it is very large $(0.155 \mathrm{c})$. This would again suggest that it is the lack of turbulence production at the lower Reynolds numbers, where viscosity becomes more dominant, that prevents correct reattachment and causes the longer bubble.

Another problem is that whilst the laminar separation point was predicted too far downstream for all Reynolds number cases, for $\operatorname{Re}=1.63 \times 10^{5}$ an even later separation point was predicted than for its higher Reynolds number counterparts, when a more upstream location should have been predicted. This is a considerable drawback because, whilst turbulent production characteristics can be tuned through turbulence quantities (discussed later in detail), it is difficult to alter the laminar separation and turbulent reattachment characteristics independently. As such, further tuning for this aspect could only be done by altering the model constants. This was not investigated in the present study as it was felt to be outside the subject of testing the applicability of the model in its standard form. 

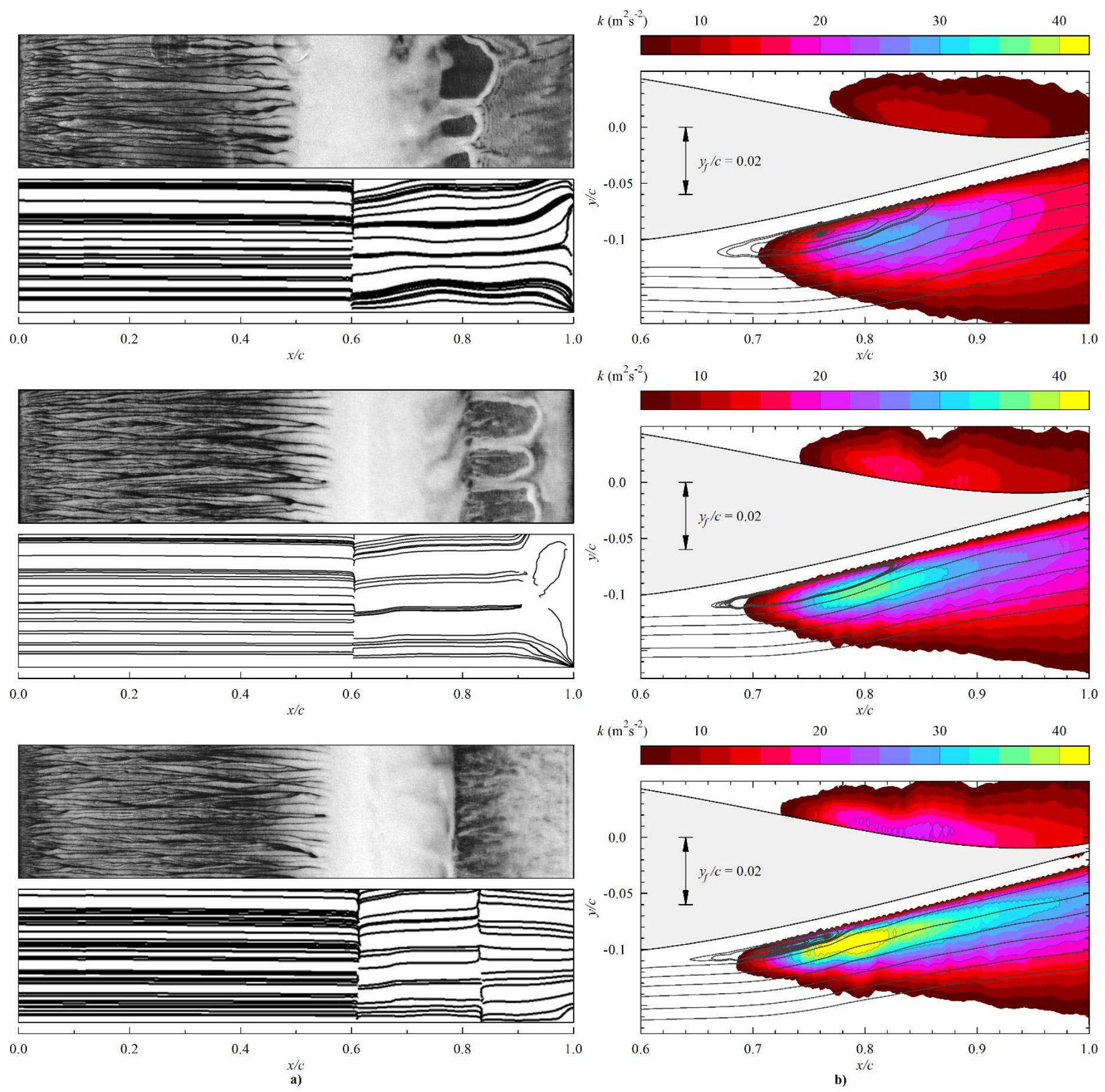

Figure 5 - Laminar separation bubble visualisation for $h / c=0.3125$ at Reynolds numbers $R e=1.63 \times 10^{5}$ (top),

$\operatorname{Re}=2.03 \times 10^{5}$ (middle), and $\operatorname{Re}=2.44 \times 10^{5}($ bottom): a) suction-surface flow visualisation (flow from left to right):

experimental oil flow (top) and CFD surface streamlines (bottom), and b) CFD velocity streamlines and contours of turbulent kinetic energy (flowfield distorted for clarity - see footnote 1). 


\subsubsection{Multi-element wing}

The force coefficients produced by the multi-element wing at $h / c=0.3125$ and varying Reynolds number, found from wind tunnel testing and CFD, are given in Table 4. It should be noted that the multi-element wing showed very little Reynolds-number sensitivity, especially compared to the single-element wing investigated previously. The estimation of both drag and downforce by the $k-k_{L^{-}}-\omega$ model is within $2.5 \%$ for downforce and $4.1 \%$ for drag, however the prediction accuracy deteriorates with decreasing Reynolds number.

Table 4 - Force coefficients at varying Reynolds number for wind tunnel tests and CFD simulation $(h / c=0.3125$, multi-element wing)

\begin{tabular}{c|c|c|c|c|c|}
$\mathbf{R e}$ & & $-\boldsymbol{C}_{\boldsymbol{L}}$ & $\boldsymbol{C}_{\boldsymbol{D}}$ & $-\boldsymbol{C}_{\boldsymbol{L}}$ Error (\%) & $\boldsymbol{C}_{\boldsymbol{D}}$ Error (\%) \\
\hline $1.63 \times 10^{5}$ & Experimental & 3.408 & 0.3962 & - & - \\
& & \pm 0.014 & \pm 0.0023 & & \\
& $k-k_{L^{-}-\omega}$ & 3.495 & 0.413 & 2.51 & 4.10 \\
& & 3.453 & 0.3920 & - & - \\
& Experimental & \pm 0.014 & \pm 0.0023 & -71 \\
& $k-k_{L^{-}} \omega$ & 3.522 & 0.407 & 1.96 & - \\
& \multirow{2}{*}{ Experimental } & 3.471 & 0.3886 & - & 3.50
\end{tabular}

A comparison of the surface-flow structures found in wind tunnel testing and CFD simulations is given in Figure 6. It should be noted that it is because of the perspective of the photographs that the inner endplate can be observed and the chord of the flap appears shorter in the experiments than in the CFD. The higher Reynolds number case, $\operatorname{Re}=2.44 \times 10^{5}$, is shown in Figure 6 a and demonstrates that the size and shape of the separation bubble on the main-plane is well predicted. The separation line that marks the start of the bubble can be observed in CFD by the point where the streamlines turn towards a spanwise rather than streamwise direction (indicating zero shear stress in the streamwise direction). This can also be seen in the wind-tunnel flow visualisation, along with the paint-accumulation line that occurs at the separation as paint inside the bubble is pushed back upstream by the reverse flow contained in the bubble. The reattachment line can be observed where the streamlines turn from a spanwise direction back towards the streamwise direction (as the $\mathrm{x}$-component of shear stress increases), this is evident in the flow visualisation because the spanwise component of flow inside the bubble is clear. 
At the wing centreline the bubble separation point and length are very similar to those of the wind tunnel flow visualisation. The separation point moves downstream closer to the endplate, due to the flaps altering the pressure distribution in that region; this is captured in the CFD. Near to the endplate, however, separation occurs slightly further downstream in CFD, and gives a slightly shorter bubble as the reattachment location is also accurate. Overall however, the prediction of the main-plane bubble is remarkably accurate. The key difference that arises on the main-plane is at the trailing edge of the central region, where for the CFD simulation turbulent trailing-edge separation occurs whereas in the wind tunnel this was not seen. The key features of the surfaceflow on the flap are also accurately predicted by the CFD simulation. The turning of flow into the spanwise direction near to the inboard edge, due to the formation of a tip vortex, is captured, as is the outboard spanwise movement close to the endplate. The formation of a small separation bubble on the flap can be seen in the CFD, although this is harder to see in the experiments and it could be that transition has occurred in the attached boundary layer due to instabilities caused by the tape that covers the joint between the two sections that the flap is built from. There is a clear accumulation line on the leading edge of the tape, indicating stagnation. However, the dark strip is at a similar location to the CFD transition bubble, and a similar location to the where the streaklines turn from streamwise to spanwise direction in Figure 6b; hence it is reasonable to conclude that this is the location of transition.

a)

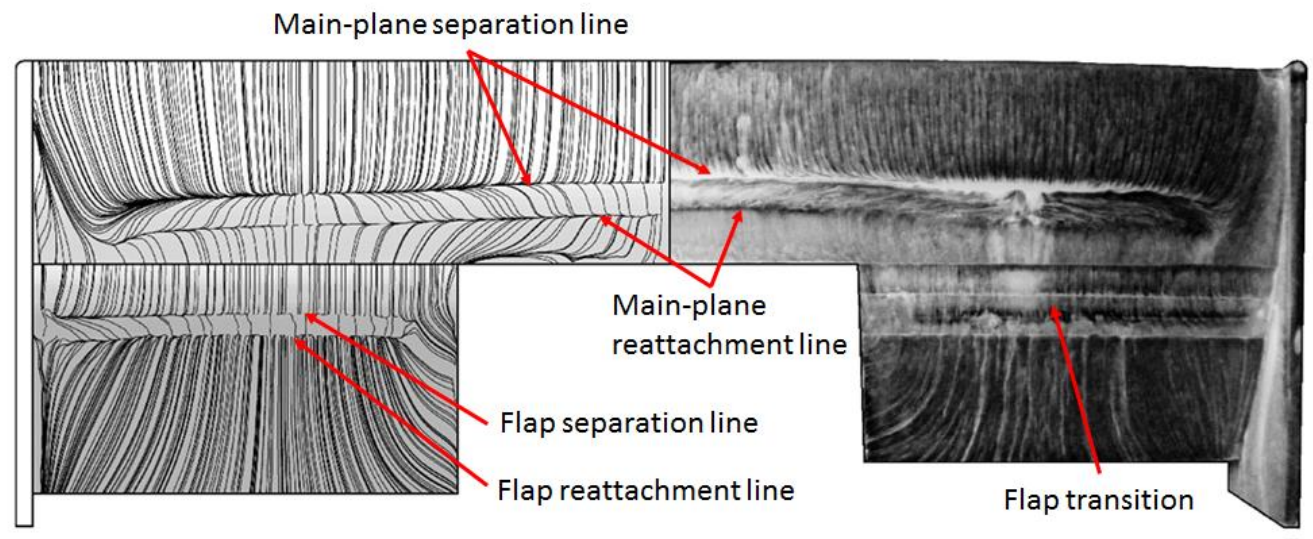

b)

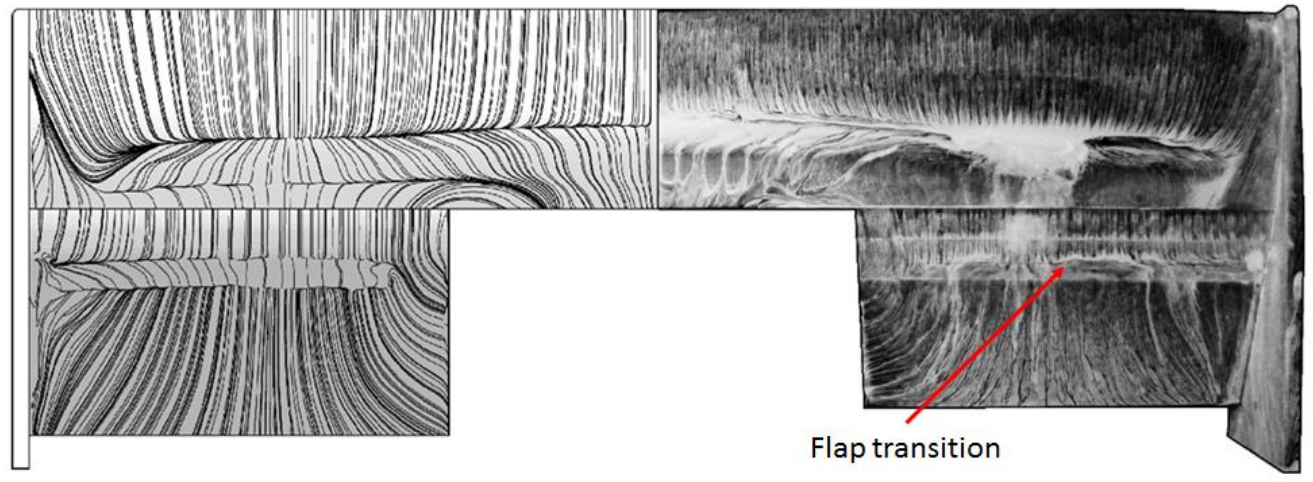

Figure 6 - Comparison of CFD surface streamlines (left) and experimental flow visualisation (right) on multi-element wing suction surfaces at a) $\operatorname{Re}=2.44 \times 10^{5}$ and $\left.b\right) \operatorname{Re}=1.63 \times 10^{5}(h / c=0.3125$, flow moving top to bottom) 
At the lowest tested Reynolds number the surface-flow characteristics, shown in Figure 6b, are again well predicted but not quite as for well as for the higher Reynolds number case. The location of separation on the main-plane is again well captured, however the length of the bubble is over-estimated by the CFD simulation, particularly in the central region. The wind tunnel flow visualisation shows that in the central region a bubble forms as usual, but then trailing-edge separation occurs. It is difficult to see from the surface streamlines alone what is happening in the CFD case, as no defined reattachment line can be seen, however the direction of the streamlines, particularly close to the flap where they curve around, appears similar to the separation characteristics seen in the flow visualisation. In the outboard region ahead of the flaps the separation line is well predicted, however observation of shear stresses in that region shows that full reattachment does not occur. The reattachment appears to be further downstream in CFD, resulting in a longer bubble. The structures on the flap are well predicted, however there is a definite bubble in the CFD case that is not particularly clear in the wind tunnel flow visualisation. Unfortunately, the join between the two sections that were bonded together to form the flap during its manufacture is very close to where the bubble is expected to form (based on the CFD result); this was not known when designing the model.

Figure 7 shows off-surface streamlines generated by velocity magnitude, and contours of turbulent kinetic energy at the wing at $z / s=2 / 3$ (flap centreline). The separation bubble is very thin, especially in comparison to that seen on the single-element wing, which is a consequence of the higher flow velocities, and thus higher local Reynolds number, underneath the wing. The contours of turbulent kinetic energy that are plotted behind the streamlines show where turbulence production occurs. Additionally, turbulent kinetic energy and the $\mathrm{x}$ component of shear stress on the suction surfaces of the main-plane and flap are given. It can be seen that no turbulent kinetic energy is produced prior to separation of the laminar boundary layer at $x / c=0.67$, as the total energy is contained solely as laminar kinetic energy. Upon reattachment, the shear stress continues to grow until the trailing edge. On the flap, similar trends can be seen, whereby laminar separation occurs at $x / c=1.25$, then the production of turbulent kinetic energy begins, and finally reattachment of the turbulent boundary layer occurs at $x / c=1.35$. 

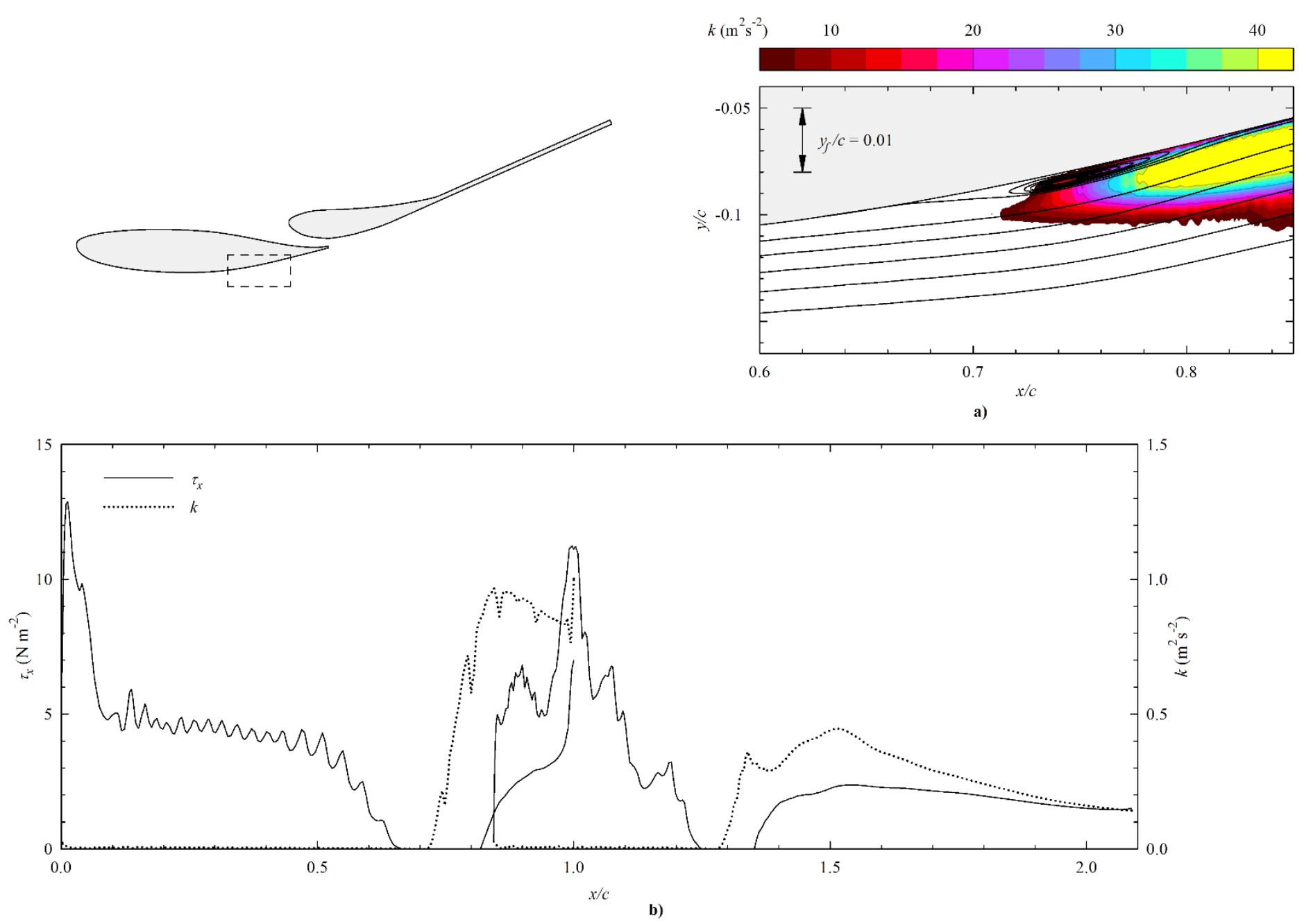

Figure 7 - a) contours of turbulent kinetic energy and off-surface streamlines (flowfield distorted for clarity - see footnote 1) and b) graph of x-component of shear stress $\left(\tau_{x}\right)$ and turbulent kinetic energy $(k)$ on the suction surfaces of the main-plane and flap at $\mathrm{z} / \mathrm{s}=2 / 3\left(\operatorname{Re}=2.44 \times 10^{5}, h / c=0.3125\right)$

There is a distinct difference in the performance of the model at different span-wise locations, in that the centre region is the most poorly predicted, in terms of surface streamlines, whilst the outboard region, ahead of the flap, is well predicted. For both of the Reynolds numbers shown in Figure 6 the outboard regions appear similar to the wind tunnel results, but in the central region the reattachment phase is somewhat lacking. The pressure distribution and shear stress on the suction surface of the wing at the main-plane centreline $(z / s=0)$ and flap centreline $(z / s=2 / 3)$ are shown in Figure 8. As expected the presence of the flap behind the outboard region has a significant effect on the pressure distribution, with a second favourable pressure gradient occurring. The significantly greater suction values generated by the main-plane in this region are possible due to the flap providing a lower pressure behind the wing to give off-surface pressure recovery; this leads to separation being less likely and the flow being more stable. In the centre section, however, separation does occur as the adverse 
pressure gradient is so much larger. Such aspects cause the shear stresses upon reattachment to be quite different. At $z / s=2 / 3$ the turbulent boundary layer causes a lot of shear stress to be produced, which is what would be expected of a turbulent boundary layer compared to its laminar counterpart. At $z / s=0$, however, the shear stresses upon reattachment are very small and then the second separation event occurs. Despite the suction values being lower for the central region, which would lead to lower shear stress developing, it is again clear that the model is not correctly replicating the turbulent reattachment phase and is, in a manner, over-estimating stall.

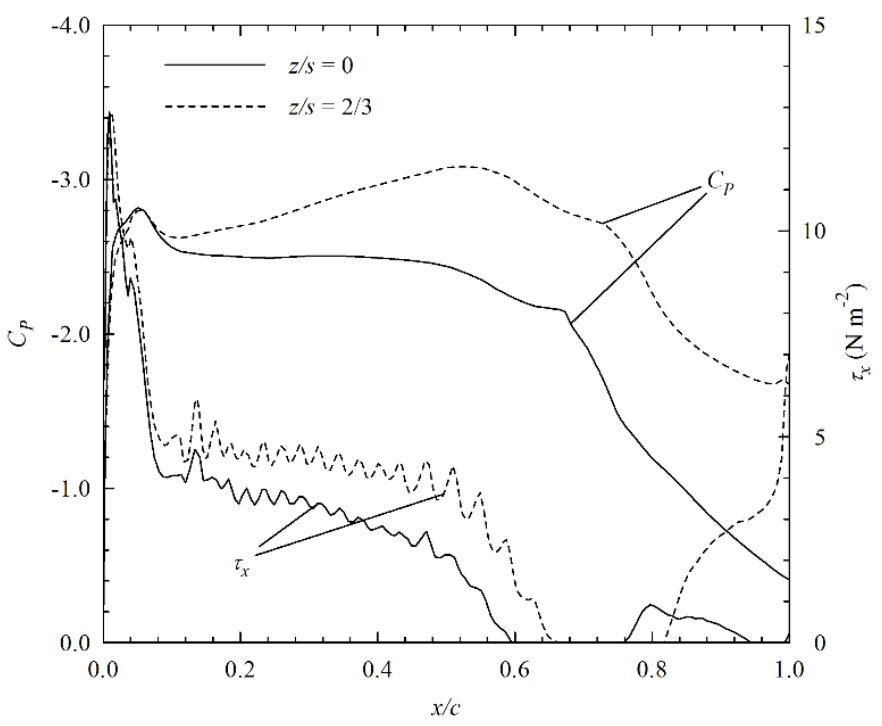

Figure $8-C_{\mathrm{P}}$ and $\tau_{\mathrm{x}}$ on main-plane suction surface at $z / s=0$ and $z / s=2 / 3$ (Multi-element wing, $\operatorname{Re}=2.44 \times 10^{5}, h / c=$ 0.3125)

\subsection{Influence of Inlet Conditions}

The $k-k_{L^{-}} \omega$ model is sensitive to inlet parameters, specifically turbulence quantities. These quantities are usually adapted in order to recreate real conditions, as their values are generally estimates. For external flows the values of turbulent kinetic energy $(k)$ and specific dissipation rate $(\omega)$ are generally estimated through prescription of turbulence intensity, which is usually related to the freestream turbulence level in the wind tunnel, and a turbulence length scale or turbulent viscosity ratio. Initial simulations here made use of a turbulence intensity of $0.5 \%$ prescribed at the inlet, which gave an intensity of $0.3 \%$ at the leading edge of the model; the same as the wind tunnel. This gives inlet value of $k=0.03375 \mathrm{~m}^{2} \mathrm{~s}^{-2}$. It was found, however, that this led to insufficient generation of turbulence during the reattachment process. Different length scales were trialled in an attempt to reduce the dissipation rate and generate more turbulence, but these were unsuccessful. Therefore, the turbulence intensity was increased to $3 \%$, which gives $k=1.215 \mathrm{~m}^{2} \mathrm{~s}^{-2}$ and is the value used in the previous 
section, in order to boost turbulence production. The large increase was made because it was hoped that a large change would occur and the effect of the parameter would be easily identifiable. The result was, as Figure 9 shows, a much closer representation of the wind tunnel results. An additional case that used an even higher turbulence intensity of $5 \%$, equivalent to $k=3.375 \mathrm{~m}^{2} \mathrm{~s}^{-2}$, was also tested.
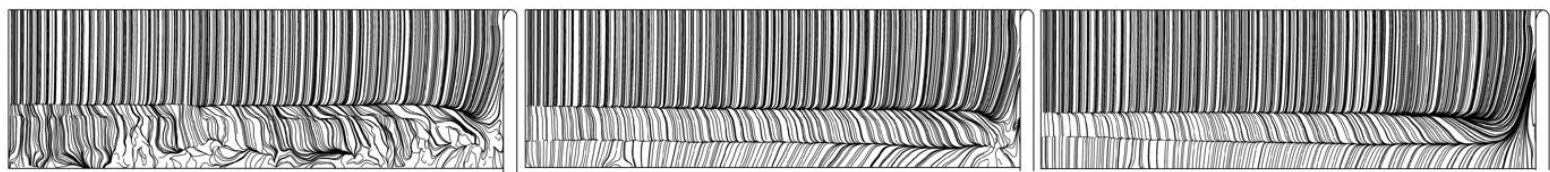

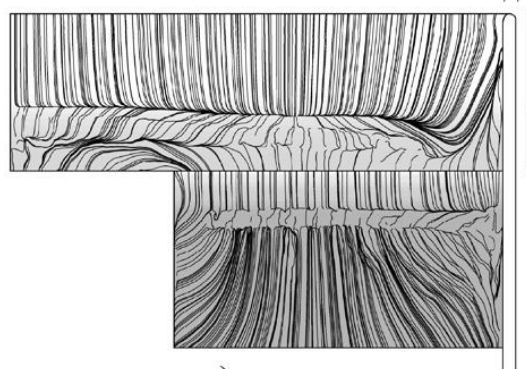

a)

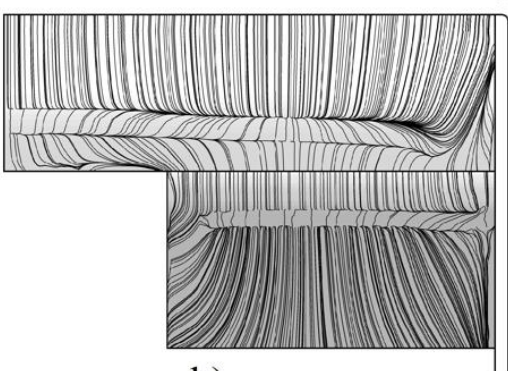

b)

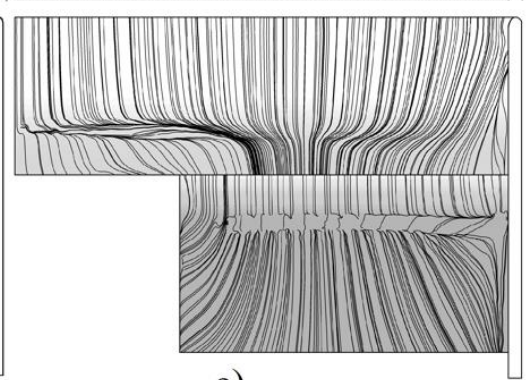

c)

Figure 9 - Suction-surface streamlines, generated by shear stress, on single-element wing (top) and multi-element wing (bottom) with inlet turbulence intensity of a) $\mathrm{Tu}=0.5 \%$, b) $\mathrm{Tu}=3 \%$, and $\mathrm{c}) \mathrm{Tu}=5 \%\left(\operatorname{Re}=2.44 \times 10^{5}\right.$, flow from top to bottom, CFD results)

The $k-k_{L^{-}} \omega$ model includes a function known as "shear sheltering". Walters \& Cokljat [33] explain that this is to dampen turbulence in thin regions of high vorticity, such as nonlinear turbulence breakdown mechanisms that occur in the pre-transitional boundary layer. Upon transition the function is restricted to the viscous sub-layer in the turbulent boundary layer. Turner [39] suggested, however, that the incorporation of such a function is inappropriate for separation-induced transition as it inhibits turbulence generation in the separated shear layer. This would be in line with what is seen in the present study, where higher turbulence intensities than those found in the wind tunnel were required in order for the model to produce enough turbulent kinetic energy to give full turbulent-boundary-layer reattachment.

The coefficients of downforce and drag generated with each inlet condition for the two wing configurations are given in Table 5. This shows, for the single-element wing, that in terms of force prediction there is little difference between the results, as in general all give similarly accurate predictions of experimentally-derived values; the exception being the $\mathrm{Tu}=5 \%$ case. The $\mathrm{Tu}=3 \%$ case gives the best prediction of downforce and drag. It must be noted, however, that the drag force is so small that these differences are all mostly negligible. For the multi-element wing there is less difference in the results. Based on comparison of the surface streamlines it would be assumed that the $\mathrm{Tu}=3 \%$ case would give the best prediction of aerodynamic forces, as 
the surface-flow structures it produced were most similar to the flow-visualisation experiments. It is, however, the $\mathrm{Tu}=5 \%$ case that contains the closest prediction to the wind tunnel force values. This is likely to be a result of the lack of force-enhancement from the bubble causing reduced downforce and drag to be produced. Hence, it is not a case of $\mathrm{Tu}=5 \%$ giving the most realistic result, just that overall the model over-predicts aerodynamic forces.

Table 5 - Comparison of wing forces generated for varying inlet turbulence intensity $\left(\operatorname{Re}=2.44 \times 10^{5}, h / c=0.3125\right)$

\begin{tabular}{c|c|c|c|c|c} 
Configuration & Case & $\mathrm{C}_{\mathrm{L}}$ & $\mathrm{C}_{\mathrm{L}}$ error $(\%)$ & $\mathrm{C}_{\mathrm{D}}$ & $\mathrm{C}_{\mathrm{D}}$ error $(\%)$ \\
\hline Single-Element & Experiment & 0.627 & - & 0.0431 & - \\
& $\mathrm{Tu}=0.5 \%$ & 0.681 & 7.93 & 0.0395 & -9.20 \\
& $\mathrm{Tu}=3 \%$ & 0.676 & 7.22 & 0.0399 & -8.01 \\
& $\mathrm{Tu}=5 \%$ & 0.744 & 15.73 & 0.0396 & -8.92 \\
& $\mathrm{Experiment}$ & 3.471 & - & 0.389 & - \\
& $\mathrm{Tu}=0.5 \%$ & 3.523 & 1.47 & 0.403 & 3.54 \\
& $\mathrm{Tu}=3 \%$ & 3.536 & 1.85 & 0.403 & 3.50 \\
& $\mathrm{Tu}=5 \%$ & 3.527 & 1.59 & 0.402 & 3.31
\end{tabular}

Inspection of the x-component of shear stress at two spanwise locations, which is given in Figure 10, shows the separation and reattachment locations in more detail. For the single-element wing the $\mathrm{Tu}=0.5 \%$ case contains the most-upstream laminar separation point; it should be noted, however, that this point is only slightly before the $\mathrm{Tu}=3 \%$ case and still much further downstream than that observed in the experiments. The boundary layer does not reattach, and what can be considered as a long bubble is produced. The Tu $=3 \%$ case, which was presented in the previous section, produces sufficient turbulence in the separated shear layer that turbulent reattachment occurs and a bubble of comparable size to that observed in the experiments is produced. The Tu= 5\% case gives the most downstream laminar separation point and shortest length bubble; additionally, it generates significantly more shear stress upon reattachment. In comparison to the wind tunnel results, considering the results presented in Section 3.1, the earlier separation point of the $\mathrm{Tu}=0.5 \%$ case combined with the earlier fully-turbulent reattachment of the $\mathrm{Tu}=5 \%$ case would give a result very close to that of the experiments in terms of bubble size and location. This result highlights why the $\mathrm{Tu}=3 \%$ case was used throughout this study, as it presented the best compromise between bubble position and reattachment 
characteristics. This also shows that an additional tuning method needs to be added to the simulation to get the pre-bubble characteristics of the $\mathrm{Tu}=0.5 \%$ case and the post-bubble characteristics of the $\mathrm{Tu}=5 \%$ case. It may be possible to achieve this by altering the model constants and therefore may warrant further investigation.
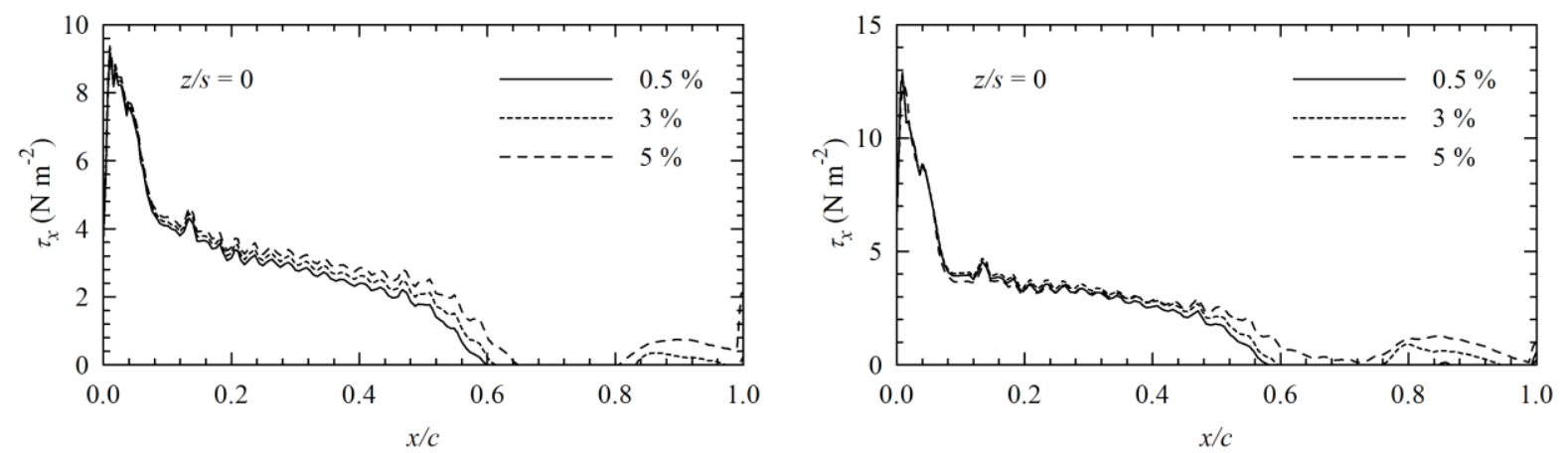

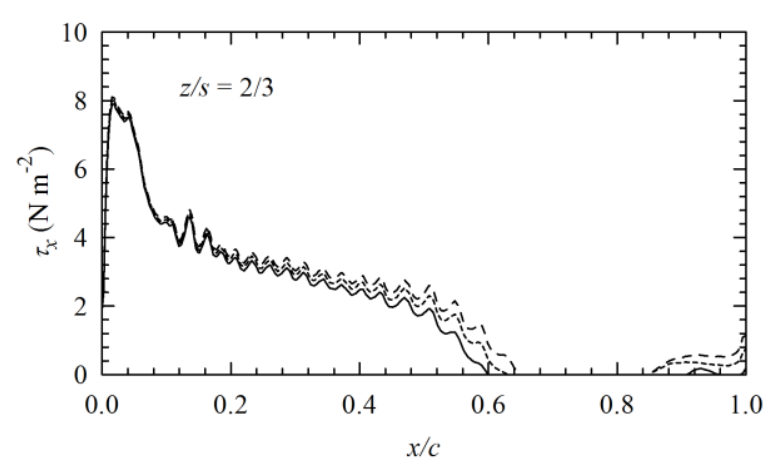

a)

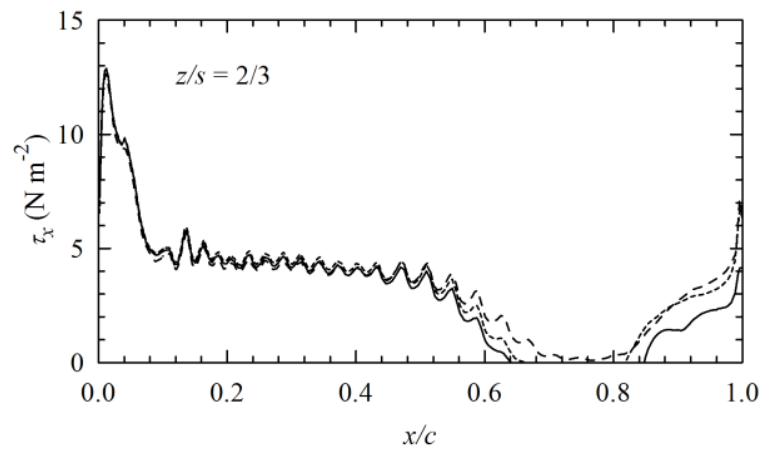

b)

Figure 10 - x-component of shear stress on suction surface of a) single-element wing, and b) multi-element wing at $z / s=0($ top) and $z / s=2 / 3$ (bottom) for varying inlet turbulence intensity

For the multi-element wing, the $\mathrm{Tu}=0.5 \%$ case again shows poor reattachment characteristics at the centre of the wing $(z / s=0)$. At the outer-span of the wing ahead of the flap, however, the prediction is better and full reattachment occurs. For $\mathrm{Tu}=3 \%$ at $z / s=0$, turbulent reattachment occurs, but the turbulent boundary layer then separates again just before the trailing edge at $x / c=0.97$, as shown in Figure $10 \mathrm{~b}$. At the outboard plane $(z / s=2 / 3)$ the turbulent boundary layer remains fully attached for all cases. For the $\mathrm{Tu}=5 \%$ case the shear stress never becomes fully zero and thus shows, similarly to the surface streamlines in Figure 9 that there is no separation bubble. Instead the instabilities grow in the laminar boundary layer enough to cause transition to a turbulent boundary layer prior to laminar separation due to the adverse pressure gradient.

The overlying trends that can be seen is this section are that as the freestream turbulence intensity is increased the laminar separation point moves downstream, the bubble becomes shorter in length, and prediction of the turbulent reattachment point is generally improved. This shows how the model is sensitive to the inlet conditions. The main concern is that because the model produces insufficient turbulent kinetic energy to give reattachment at wind tunnel freestream turbulence intensity, it has to be artificially increased. Therefore, for 
cases where wind tunnel results are not available a priori in order to validate, and in some way calibrate, the model it may be difficult to obtain accurate predictions.

\subsection{Comparison of Transition-Sensitive \& Fully-Turbulent Closure Models}

The majority of the present study has revolved around the prediction of transition phenomena. In order to show the importance of simulating such aspects through the use of transitional closure models, comparisons to a classical fully-turbulent approach are made in this section. As the $k-k_{L}-\omega$ model is based on the $k-\omega$ framework it was deemed appropriate that the $k$ - $\omega S S T$ model should be used as the fully-turbulent model for comparison. It was noted previously that the separation bubble was smaller on the multi-element wing than on the singleelement wing and thus had a reduced effect on the performance of the wing, in particular its sensitivity to Reynolds number. It was postulated that the diminished effect of the separation bubble may eliminate the requirement for a transition-sensitive closure model, hence the $k-k_{L^{-}} \omega$ and $k-\omega S S T$ models were compared.

Table 6 - Downforce and drag coefficients predicted by each closure model compared to experimental results $\left(\operatorname{Re}=2.44 \times 10^{5}, h / c=0.3125\right)$

\begin{tabular}{c|c|c|c|c|c|} 
Configuration & Case & $C_{L}$ & $C_{D}$ & $C_{L}$ error & $C_{D}$ error \\
\hline Single-Element & Experiment & 3.471 & 0.389 & - & - \\
& $k-k_{L}-\omega$ & 3.536 & 0.403 & $1.85 \%$ & $3.50 \%$ \\
& $k-\omega \mathrm{SST}$ & 3.161 & 0.405 & $-9.79 \%$ & $3.99 \%$ \\
\multirow{3}{*}{ Multi Element } & Experiment & 0.627 & 0.0431 & - & - \\
& $k-k_{L}-\omega$ & 0.676 & 0.0399 & $7.22 \%$ & $-8.01 \%$ \\
& $k-\omega \mathrm{SST}$ & 0.565 & 0.0442 & $-11.00 \%$ & $2.52 \%$
\end{tabular}

It was shown in the previous section that the $k-k_{L^{-}}-\omega$ model required the turbulence intensity to be increased, above the measured wind tunnel level, in order artificially to increase turbulent kinetic energy to give successful reattachment of the separated shear layer. Such an aspect is not required for the $k-\omega$ SST model as no such deficiency has been cited in previous studies. Therefore, the inlet turbulence intensity was prescribed at $0.5 \%$; owing to the dissipation of turbulence this gives an intensity of $0.3 \%$ at the leading edge of the wing, which is equivalent to the wind tunnel conditions. 
The drag and downforce coefficients calculated by the two models are compared to the experimental result in Table 6. The fully-turbulent $k-\omega S S T$ model gives a poorer estimate of both downforce and drag compared to the transitional model - much more so in terms of downforce, which is substantially under-estimated.

It is clear that the separation bubble is an integral component of the surface-flow structure. To highlight the difference between the prediction given by transitional and fully-turbulent closure models, Figure 11 shows surface streamlines from $k-k_{L^{-}} \omega$ and $k-\omega S S T$. For the latter, the fully turbulent boundary layer which forms from the leading edge of the model means that no laminar separation occurs, and thus the bubble does not form, and instead turbulent separation occurs close to the trailing edge [11]. The important difference, therefore, is that the $k-k_{L^{-}} \omega$ model allows a laminar separation to occur whilst the $k$ - $\omega S S T$ model only contains turbulent separations. The difference between such separation phenomena is that a turbulent boundary layer is more resilient to the adverse pressure gradient, due to fluctuating velocity components giving momentum transfer normal to the surface, and thus separation occurs at a more downstream location.

The trailing-edge separation which occurs in the $k$ - $\omega S S T$ result causes the under-prediction of downforce, as circulation is reduced. The higher drag coefficient, compared to the $k-k_{L}-\omega$ model, occurs because of the greater shear stresses caused by the turbulent boundary layer that stretches across the entire suction surface, compared to the laminar boundary layer of the transitional model. Comparisons between the two models' static pressure, total pressure, and turbulent kinetic energy are given in Figure 12. Comparisons are made at $z / s=0$ (main-plane centreline) for the single-element wing and at $z / s=2 / 3$ (flap centreline) for the multi-element configuration. It should be noted that both wing configurations display similar characteristics, principally on the main-plane but to a lesser extent on the flap. As expected based on the force coefficients given in Table 6 , the $k$ - $\omega S S T$ model gives less suction on the lower wing surface $\left(\Delta \mathrm{C}_{\mathrm{P}}<0\right)$ and less pressure on the upper surface $\left(\Delta \mathrm{C}_{\mathrm{P}}>0\right)$. Clearly the pressure field is significantly different between the two models, with the $k-k_{L}-\omega$ model giving a $\Delta \mathrm{C}_{\mathrm{P}}<0.24$ on the lower surface. This occurs in two locations, the suction peak close to the leading edge and where the separation bubble occurs. Previous studies have shown the separation bubble to be a force-enhancement mechanism as it alters the effective shape of the wing to give it more effective camber; this helps to maintain suction levels and increase circulation [10-11]. It is the increase in circulation that causes suction across the entire lower surface to be increased. In addition to altering the aerodynamic forces that the wing generates, changes to the pressure field on a three-dimensional wing can also affect the formation of wing-tip vortices. The smaller pressure difference between the upper and lower surfaces of the $k$ - $\omega S S T$ model weakens the formation of such vortices. 
a)

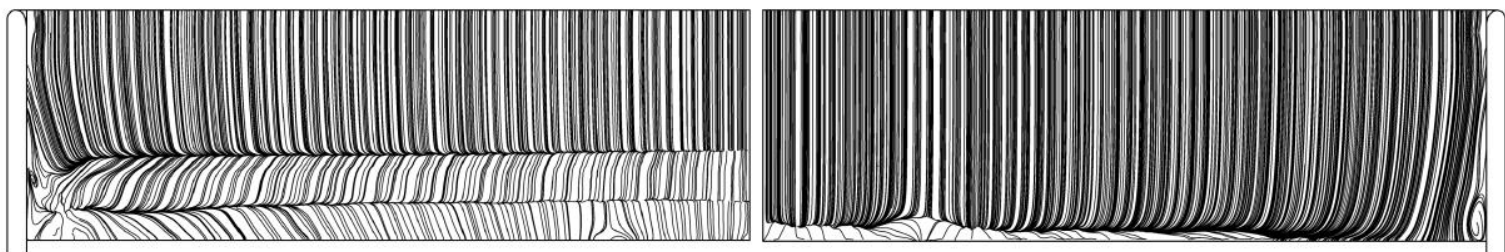

b)

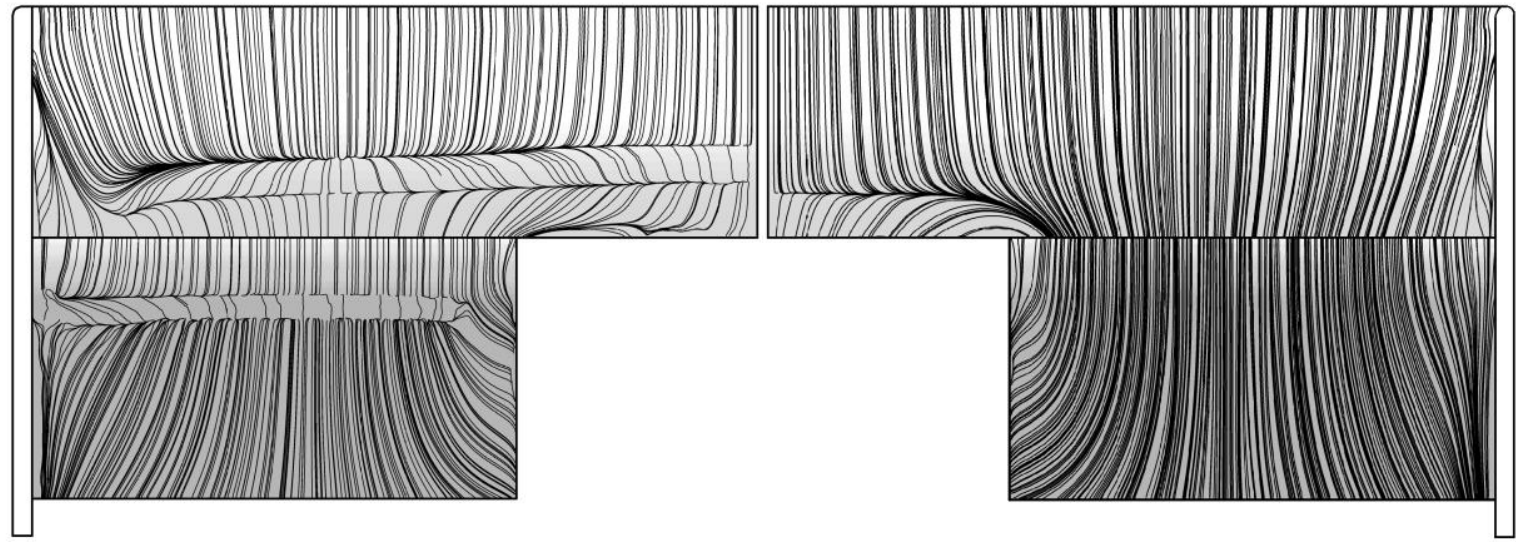

Figure 11 - Comparison of suction-surface streamlines generated by $k-\omega S S T$ (left) and $k-k_{L}-\omega$ (right) on a) singleelement wing and $b)$ multi-element wing $\left(\operatorname{Re}=2.44 \times 10^{5}, h / c=0.3125\right.$, flow from top to bottom)

Figure 12b shows turbulent kinetic energy distribution around the wing. Due to the $k-k_{L^{-}} \omega$ model also including laminar kinetic energy, there is no production of turbulent kinetic energy until transition occurs in the free shear layer of the separation bubble. The negative values of $\Delta k$ upstream of $x / c \approx 0.65$ close to the surface show the turbulent boundary layer formed by the $k-\omega S S T$ model, which begins to grow from close to the leading edge. For the $k-k_{L}-\omega$ model, as shown in previous sections, there is no production of turbulent kinetic energy until $x / c \approx 0.65$, with the maximum occurring at $x / c=0.775$. The key difference is that the $k-\omega S S T$ model produces the majority of its turbulent kinetic energy on the forward half of the wing and little at the trailing edge, whilst the $k-k_{L}-\omega$ model produces none at the leading edge and a lot at the trailing edge. The fact that only positive values of $\Delta k$ occur downstream of $x / \mathrm{c} \approx 0.7$ shows that the wake of the wing with the $k-k_{L^{-}}-\omega$ model contains more turbulent kinetic energy than the $k-\omega S S T$ prediction; hence the turbulent flow behind the wing is very different. 

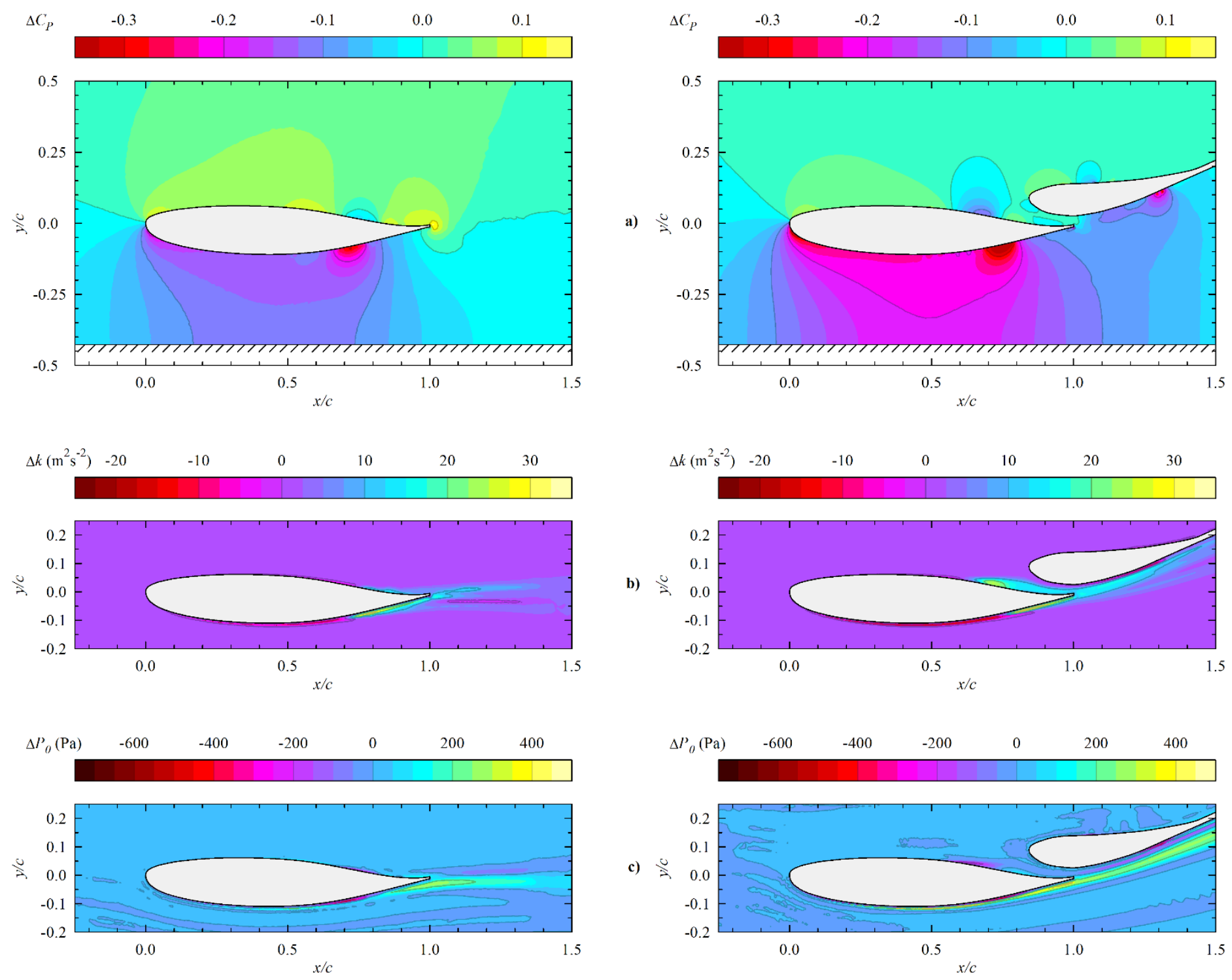

Figure 12 - Comparison of closure models at $z / s=2 / 3$ (flap centreline) for single-element (left) and multi-element (right) wings: contours of a) $\left.\Delta \mathrm{C}_{\mathrm{P}}, \mathrm{b}\right) \Delta \mathrm{k}$, and c) $\Delta \mathrm{P}_{0}\left(k-k_{L^{-}} \omega-k-\omega S S T, \operatorname{Re}=2.44 \times 10^{5}, h / c=0.3125\right)$

A comparison of the wing's wake profiles produced by the two models is given through observation of contours of total pressure loss. The positive values of $\Delta \mathrm{P}_{0}$ upstream of $\mathrm{x} / \mathrm{c} \approx 0.6$ shows the thicker boundary layer that occurs in the $k-\omega S S T$ prediction due to the turbulent boundary layer it produces from the leading edge, compared to the thinner laminar boundary layer of the $k-k_{L}-\omega$ model. The negative values of $\Delta \mathrm{P}_{0}$ in the approximate region $0.6<x / c<0.8$, which is where the separation bubble occurs, appear to be due to the 'dead air' inside the bubble giving low total pressure values. After the bubble and close to the trailing edge $\Delta \mathrm{P}_{0}$ again becomes positive, which indicates the thicker wake that is produced by the $k-\omega S S T$ model due to the trailingedge separation it predicts. In all instances there is little difference in the flow from the top (pressure) surfaces, including on the multi-element wing's flap, it is just the thickness of the wake a short distance from the surface 
that is the key difference. It is likely that the top surface flow characteristics are not too dissimilar due to the large flow acceleration through the slot gap and the lack of large adverse pressure gradients on these surfaces.

\section{CONCLUSIONS}

It has been shown in the current work that the transition-sensitive RANS closure model $k-k_{L^{-}} \omega$ is capable of giving accurate results, both in terms of surface structures and aerodynamic forces when compared to wind tunnel results for wings operating in ground effect. Additionally, the results given by the transition-sensitive model were compared to those produced by the fully-turbulent $k-\omega S S T$ model, and this highlighted the importance of including laminar and transitional flows in such simulations.

A significant sensitivity to Reynolds number was found to exist for the $k-k_{L}-\omega$ model when modelling the single-element wing. At the higher tested Reynolds numbers accurate predictions of drag and downforce coefficients were given, but as the Reynolds number was decreased these began to deteriorate. The issue stemmed from the model's failure to represent correctly the turbulent reattachment phase of the separation bubble and subsequent turbulent trailing-edge separation. This was, however, also due to the laminar separation point occurring further downstream than in the wind tunnel tests. These problems appeared to be limited to the region close to the surface, in that streamlines would move back towards the surface at the correct location but not fully reattach with it. Consequently, observation of off-surface streamlines appeared to be in line with what was expected. Additionally, the model was able to provide a result in which, as the Reynolds number increased, the height of the bubble reduced; as it should.

Although some Reynolds number sensitivity was evident for the multi-element wing, it was significantly reduced compared to the single-element configuration. Although the surface-flow structures were well predicted at both the highest and lowest tested Reynolds numbers, the estimation of aerodynamic forces compared to experimental values improved as the Reynolds number increased. With a maximum error of $2.51 \%$ in downforce and $4.1 \%$ in drag, however, the results for the lowest tested Reynolds number case are by no means inaccurate. The lack of Reynolds-number sensitivity, however, may in part be due to the lack of sensitivity of the geometry in general. The model performed better at outboard regions (ahead of the flaps) than in the central section, which showed that the model becomes worse in areas of greater adverse pressure gradients and turbulent flow separations.

The model was shown to be sensitive to inlet conditions, specifically the value of turbulence intensity. This value had to be increased to $\mathrm{Tu}=3 \%$, much higher than the $\mathrm{Tu}=0.5 \%$ required to recreate the wind tunnel 
conditions, in order to give the most accurate recreation of surface flow structures. This stemmed from the model producing insufficient turbulent kinetic energy in the separated shear layer, and as a result, reattachment of the turbulent boundary layer being inhibited. Further increasing this value to $\mathrm{Tu}=5 \%$ led to elimination of the separation bubble. Overall, increasing turbulence intensity at the inlet led to the laminar separation point being delayed, turbulent reattachment occurring further upstream, and thus a shorter bubble being given. These issues mean that it may be difficult to use the model in circumstances where no experimental results are available for comparison.

Although there are still some deficiencies with the transitional model, when compared to the results of the fully-turbulent model it gave considerably better results. The key difference is that the fully-turbulent nature of the $k-\omega S S T$ model means that no separation bubble is predicted, and it is instead replaced by the occurrence of trailing-edge separation. This leads to dramatically incorrect surface structures, compared to the experiments. Although the prediction of drag was very good, almost comparable to that given by the $k-k_{L^{-}} \omega$ model, there was a large under-estimation of downforce, a result of the lack of force enhancement stemming from the separation bubble's elimination. In comparison to the $k-k_{L^{-}} \omega$ model, the $k$ - $\omega S S T$ predicted a thicker wake, due to the trailing-edge separation, and significantly less turbulent kinetic energy. Moreover, differences in pressure field between the two models were evident. The front wing of a racing car is arguably its most important aerodynamic feature, as it defines the operating conditions for features placed downstream of it. It is, therefore, important to represent the off-surface flow characteristics correctly as well as to predict aerodynamic forces accurately. The significant differences between the results given by the two models highlight the consequences of correct turbulence model choice, particularly whether a fully-turbulent formulation is a realistic approach.

The present study has highlighted the importance of including transitional effects in simulations of wings operating in ground effect and shown that such a task can be accomplished with a steady-state RANS method using eddy-viscosity closure models in a commercial solver. The sectional forces and on- and off-surface flow structures were well captured and a significant improvement over the fully-turbulent closure model was provided. Overall, the $k-k_{L^{-}} \omega$ model has been shown to be appropriate for the simulation of separation-induced transition on a wing operating in ground effect. 


\section{REFERENCES}

[1] W. J. Jasinski and M. S. Selig, "Experimental Study of Open-wheel Race Car Front Wings," SAE Paper 98-3042, 1998.

[2] K. Knowles, D. T. Donogue and M. V. Finnis, “A Study of Wings in Ground Effect," in RAeS Vehicle Aero Conf, Loughborough, UK, 1994.

[3] R. Ranzenbach and J. B. Barlow, “Two-Dimensional Airfoil in Ground Effect, An Experimental and Computational Study," SAE Paper 94-2509, 1994.

[4] R. Ranzenbach and J. B. Barlow, "Cambered Airfoil in Ground Effect - Wind Tunnel and Road Conditions," AIAA paper no. 95-1909, 1995.

[5] R. Ranzenback and J. B. Barlow, "Cambered Airfoil in Ground Effect: An Experimental and Computational Study," SAE Paper 96-0909, 1996.

[6] R. Ranzenbach and J. B. Barlow, "Multi-element Airfoil in Ground Effect- an Experimental and Computational Study,” AIAA paper no. 97-2238, 1997.

[7] X. Zhang and J. Zerihan, "Aerodynamics of a Double Element Wing in Ground Effect," AIAA Journal, vol. 45, no. 6, pp. 1007-1016, 2003.

[8] X. Zhang and J. Zerihan, "Edge Vortices of a Double-Element Wing in Ground Effect," Journal of Aircraft, vol. 41, no. 15, pp. 1127-1137, 2004.

[9] J. Zerihan and X. Zhang, "Aerodynamics of a Single-Element Wing in Ground Effect," Journal of Aircraft, vol. 37, no. 6, pp. 1058-1064, 2000.

[10] J. Correia, L. S. Roberts, M. V. Finnis and K. Knowles, "Scale Effects on a Single-Element Inverted Wing in Ground Effect," The Aeronautical Journal, vol. 118, part 1205, pp. 797-809 2014.

[11] L. S. Roberts, J. Correia, M. V. Finnis and K. Knowles, "Forcing Boundary-Layer Transition on a Single-Element Wing in Ground Effect," ASME Journal of Fluids Engineering, vol. 139, no. 10, pp. 101205$10125-12,2017$

[12] L. S. Roberts, M. V. Finnis , K. Knowles \& N. Lawson, "Forcing Boundary-Layer Transition on an Inverted Airfoil in Ground Effect," Journal of Aircraft, published online 18 July, 2017, DOI 10.2514/1.C034304.

[13] L. S. Roberts, J. Correia, M. V. Finnis and K. Knowles, “Aerodynamic Characteristics of a Wing \& Flap Configuration in Ground Effect \& Yaw,” Proc. IMechE Pt. D: J. Automobile Engineering vol. 230, no. 6, pp. 841-854, 2016. 
[14] V. Galoul and T. J. Barber, "A Study of an Inverted Wing with Endplates in Ground Effect," Proc. 16th Australasian Fluid Mechanics Conference, pp. 914-919, Gold Coast, Australia, 2007.

[15] J. W. Vogt and T. J. Barber, "Variation of Ground Effect Phenomena about Downforce Generating Tyrrell and NACA4412 Aerofoils,” International Journal of Aerodynamics, vol. 1, no. 1, pp. 82-96, 2010.

[16] J. W. Vogt, T. J. Barber and E. Leonardi, "Flow Field Phenomena about Lift and Downforce Generating Cambered Aerofoils in Ground Effect," Proc. 16th Australasian Fluid Mechanics Conference, pp. 328-335, Gold Coast, Australia, 2007.

[17] S. Mahon and X. Zhang, "Computational Analysis of Pressure and Wake Characteristics of an Aerofoil in Ground Effect,” ASME Journal of Fluids Engineering, vol. 127, no. 2, pp. 290-298, 2004.

[18] S. Mahon and X. Zhang, "Computational Analysis of an Inverted Double-Element Airfoil in Ground Effect,” ASME Journal of Fluids Engineering, vol. 128, part. 6, pp. 1172-1180, 2006.

[19] W. A. Mokhtar, “Aerodynamics of High-Lift Wings with Ground Effect for Racecars,” SAE Technical Paper 2008-01-0656, 2008.

[20] W. A. Mokhtar and J. Lane, "Racecar Front Wing Aerodynamics," SAE Technical Paper 2008-012988, 2008.

[21] J. Molina and X. Zhang, "Aerodynamics of a Heaving Airfoil in Ground Effect,” AIAA Journal, vol. 49, no. 6, pp. 1168-1179, 2011.

[22] J. Molina, X. Zhang and D. Angland, "On the Unsteady Motion and Stability of a Heaving Airfoil in Ground Effect,” Acta Mechanica Sinica, vol. 27, no. 2, pp. 164-178, 2011.

[23] J. W. Vogt and T. J. Barber, "Variation of Ground Effect Phenomena About Downforce Generating Aerofoils Caused by Changes in Aerofoil Shape," International Journal of Aerodynamics, vol. 2, no. 1, pp. 3649, 2012.

[24] Z. Vlahostergios, K. Yakinthos and A. Goulas, "Separation-induced Boundary Layer Transition: Modelling with a Non-linear Eddy-viscosity Model Coupled with the Laminar Kinetic Energy Equation," International Journal of Heat and Fluid Flow, vol. 30, pp. 617-636, 2009.

[25] M. S. Genç, "Numerical Simulation of Flow Over a Thin Aerofoil at a High Reynolds Number Using a Transition Model," Proceedings of the Institution of Mechanical Engineers, Part C: Journal of Mechanical Engineering Science, vol. 224, no. 10, pp. 2155-2164, 2010. 
Aerofoil Flows Without/With Single and Simultaneous Blowing and Suction," European Journal of Mechanics B/Fluids, vol. 30, pp. 218-235, 2011.

[27] L. Wang, S. Fu, A. Carnarius, C. Mockett and F. Thiele, "A Modular RANS Approach for Modelling Laminar-Turbulent Transition in Turbomachinery Flows," International Journal of Heat and Fluid Flow, vol. 34, pp. 69-69, 2012.

[28] B. Shome, "Numerical Study of Oscillating Boundary Layer Flow Over a Flat Plate Using $k-k_{L^{-}} \omega$ Turbulence Model,” International Journal of Heat and Fluid Flow, vol. 42, pp. 131-138, 2013.

[29] A. Crivellini and V. D'Alessandro, "Spalart-Allmaras Model Apparent Transition and RANS Simulations of Laminar Separation Bubbles on Airfoils," International Journal of Heat and Fluid Flow, vol. 47, pp. 70-83, 2014.

[30] G. Castiglioni, J. A. Domaradzki, V. Pasquariello, S. Hickel and M. Grilli, "Numerical Simulations of Separated Flows at Moderate Reynolds Numbers Appropriate for Turbine Blades and Unmanned Aero Vehicles," International Journal of Heat and Fluid Flow, vol. 49, pp. 91-99, 2014.

[31] J. Keogh, G. Doig and S. Diasinos, "Flow Compressibility Effects Around an Open-Wheel Racing Car", The Aeronautical Journal, vol. 118, no. 1210, pp. 1409-1430, 2014.

[32] J. Keogh, G. Doig, S. Diasinos and T. Barber, "The Influence of Cornering on the Vortical Wake Structures of an Inverted Wing", Proceedings of the Institution of Mechanical Engineers, Part D: Journal of Automobile Engineering, vol. 229, no. 13, pp. 1817-1829, 2015.

[33] D. K. Walters and D. Cokljat, "A Three-Equation Eddy-Viscosity Model for Reynolds-Averaged Navier-Stokes Simulations of Transitional Flow," ASME Journal of Fluids Engineering, vol. 130, part 12, pp. 121401-121401-14, 2008.

[34] D. K. Walters and J. H. Leylek, "A New Model for Boundary Layer Transition Using a Single-Point RANS Approach,” ASME J. Turbomach., vol. 126, pp. 193-202, 2004.

[35] K. Knowles and M. V. Finnis, "Development of a New Open-jet Wind Tunnel and Rolling Road Facility," in 2nd MIRA International Conference on Vehicle Aerodynamics, Coventry, UK. MIRA Ltd., Nuneaton, 1998.

[36] M. Lanfrit, "Best Practice Guidelines for Handling Automotive External Aerodynamics with FLUENT,"Version 1.2, Guide, Darmstadt: Fluent Deutschland GmbH, 2005. 
[37] A. Shelton, J. Abras, R. Jurenko and M. Smith, "Improving the CFD Predictions of Airfoils in Stall," in 43rd AIAA Aerospace Sciences Meeting and Exhibit, Reno, NV, USA, 2005.

[38] S. S. Diwan and O. N. Ramesh, "Laminar Separation Bubbles: Dynamics and Control," Sadhana, vol. 32, no. 1, pp. 103-109, 2007.

[39] C. Turner, "Laminar Kinetic Energy Modelling for Improved Laminar-Turbulent Transition Prediction," PhD Thesis, The University of Manchester, 2012. 